San Jose State University

SJSU ScholarWorks

Master's Theses

Master's Theses and Graduate Research

1993

\title{
A Needs assessment for evaluation assistance among members of the Community Partnership of Santa Clara County
}

Delyna A. Cruz

San Jose State University

Follow this and additional works at: https://scholarworks.sjsu.edu/etd_theses

\section{Recommended Citation}

Cruz, Delyna A., "A Needs assessment for evaluation assistance among members of the Community Partnership of Santa Clara County" (1993). Master's Theses. 622.

DOI: https://doi.org/10.31979/etd.akph-38mc

https://scholarworks.sjsu.edu/etd_theses/622

This Thesis is brought to you for free and open access by the Master's Theses and Graduate Research at SJSU ScholarWorks. It has been accepted for inclusion in Master's Theses by an authorized administrator of SJSU ScholarWorks. For more information, please contact scholarworks@sjsu.edu. 


\section{INFORMATION TO USERS}

This manuscript has been reproduced from the microfilm master. UMI films the text directly from the original or copy submitted. Thus, some thesis and dissertation copies are in typewriter face, while others may be from any type of computer printer.

The quality of this reproduction is dependent upon the quality of the copy submitted. Broken or indistinct print, colored or poor quality illustrations and photographs, print bleedthrough, substandard margins, and improper alignment can adversely affect reproduction.

In the unlikely event that the author did not send UMI a complete manuscript and there are missing pages, these will be noted. Also, if unauthorized copyright material had to be removed, a note will indicate the deletion.

Oversize materials (e.g., maps, drawings, charts) are reproduced by sectioning the original, beginning at the upper left-hand corner and continuing from left to right in equal sections with small overlaps. Each original is also photographed in one exposure and is included in reduced form at the back of the book.

Photographs included in the original manuscript have been reproduced xerographically in this copy. Higher quality $6^{\prime \prime} \times 9^{\prime \prime}$ black and white photographic prints are available for any photographs or illustrations appearing in this copy for an additional charge. Contact UMI directly to order.

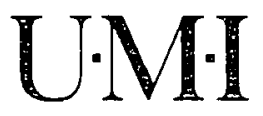

University Microfilms international

A Bell \& Howell Information Company 

Order Number 1354137

A needs assessment for evaluation assistance among members of the community partnership of Santa Clara County

Cruz, Delyna Aileen, M.P.H.

San Jose State University, 1993

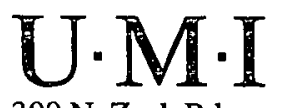





\title{
A Needs Assessment for Evaluation Assistance \\ Among Members of the \\ Community Partnership of \\ Santa Clara County
}

\author{
A Thesis \\ Presented to \\ The Faculty of the Department of Health Science \\ San Jose State University
}

\author{
In Partial Fulfillment \\ of the Requirements for the Degree \\ Master of Public Health
}

By

Delyna A. Cruz

August, 1993 
APPROVED FOR THE DEPARTMENT OF HEALTH SCIENCE

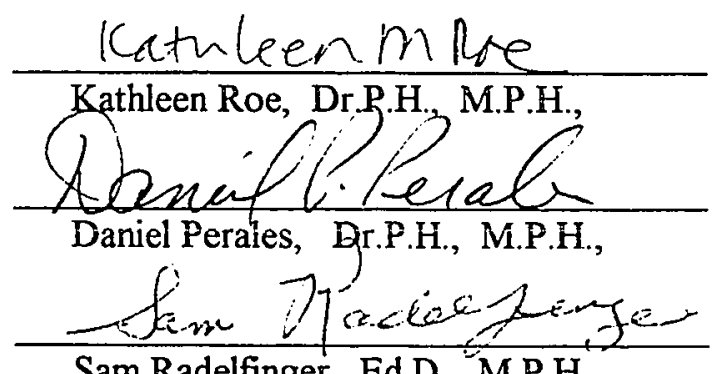

Sam Radelfinger, Ed.D., M.P.H.

\section{APPROVED FOR THE UNIVERSITY}

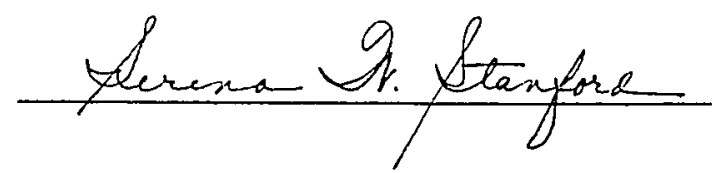




\section{ABSTRACT \\ AN ASSESSMENT OF THE EVALUATION NEEDS AND CAPACITIES WITHIN THE COMMUNITY PARTNERSHIP OF SANTA CLARA COUNTY \\ by Delyna A. Cruz}

This thesis was conducted to determine the evaluation needs and capacities of member agencies within the Community Partnership of Santa Clara County. It examines Community Partnership member agencies' perceived evaluation capacities, perceived importance of evaluation, and perceived needs for evaluation assistance.

Results of this research indicated that most Community Partnership member agencies are required to conduct program evaluation. Respondents generally viewed evaluation as an important component of their programs. Although many respondents rated their agencies as adequate or strong in evaluation objectives, data collection, data analysis, and reporting results, most would like assistance to improve their organization's evaluation capacity. Most respondents indicated an interest in an evaluation workshop, or series of workshops as opposed to one-on-one technical assistance. 


\section{ACKNOWLEDGEMENTS}

I would like to acknowledge my appreciation for the many special people who have assisted me through the process of this thesis.

First of all, to my first reader, Kathleen Roe, Dr.P.H., M.P.H., whose encouragement and excellent ability to critique and edit helped me through this endeavor. The endless support and knowledge offered by Kathleen will forever be remembered and appreciated.

To Daniel Perales, Dr.P.H., M.P.H., whose expertise in data analysis, positive feedback, and sincere interest in this research gave me an additional incentive to continue.

To Sam Radelfinger, Ed.D., M.P.H., who offered his ideas and expertise in instrument development and data collection which helped make data collection as smooth as possible.

A final acknowledgment to my boyfriend Matteo Tanzi who offered endless support and devoted his valuable time to help proofread this thesis, to offer suggestions and ideas, and to cook dinner for me when I did not have the time. 


\section{TABLE OF CONTENTS}

\section{Page}

List of Tables

viii

List of Figures

ix

\section{Chapter 1}

INTRODUCTION

Purpose

1

Statement of the Problem

Limitations

5

Significance

6

Chapter 2

REVIEW OF LITERATURE $\quad 8$

History of Evaluation 9

$\begin{array}{ll}\text { Importance of Evaluation } & 10\end{array}$

Need for Evaluation Assistance 11

$\begin{array}{ll}\text { Evaluation Methodology } & 12\end{array}$

$\begin{array}{lr}\text { Process and Outcome Evaluation } & 12\end{array}$

Other Models 14

$\begin{array}{ll}\text { Implementation } & 15\end{array}$

Internal vs. External Evaluators 16

Evaluation of the Community Partnership 16 
Chapter 3

$\begin{array}{lr}\text { METHODOLOGY } & 18\end{array}$

$\begin{array}{ll}\text { Research Objectives } & 18\end{array}$

$\begin{array}{ll}\text { Definitions } & 19\end{array}$

$\begin{array}{ll}\text { Study Design } & 20\end{array}$

Questionnaire 21

Sample $\quad 22$

Telephone Protocol 22

Informed Consent 23

Analysis $\quad 24$

Assumptions $\quad 24$

Chapter 4

RESULTS 26

Chapter 5

DISCUSSION 44

Evaluation Capacities of Member Agencies $\quad 44$

Perceived Importance of Evaluation Among Member Agencies 45

Need for Evaluation Assistance Among Member Agencies 45

Discussion of Methods $\quad 47$

Selection of Participants $\quad 47$

Timing of Data Collection $\quad 49$

Trust 51

Contributions of the Research 51 
Chapter 6

RECOMMENDATIONS

Recommendations to Community Partnership Evaluation Team 53

Recommendations to Community Partnership Staff 54

Recommendations for Evaluation of Community Based Programs 55

$\begin{array}{ll}\text { REFERENCES } & 57\end{array}$

BIBLIOGRAPHY $\quad 59$

APPENDICES
A. List of Evaluation Team Members 60
B. Partnership's First Year Evaluation Goals 61
C. Questionnaire 66
D. Script for Interviews 69
$\begin{array}{ll}\text { E. Human Subjects Approval } & 71\end{array}$ 


\section{LIST OF TABLES}

Table

Page

1. Results of Attempted Data Collection Calls 26

2. Evaluation Requirements by Funding Source 27

3. Frequency of Evaluation Within Organizations 28

4. Evaluation Staffing 29

5. Perceived Capacity in Aspects of Evaluation 31

6. Perceived Importance of Aspects of Evaluation 35

7. Perceived Need for Evaluation Assistance 38

8. Perceived Importance of Evaluation Among Members 42

Who Do Not Conduct Evaluation

9. Consideration of Conducting Evaluation 43 


\section{LIST OF FIGURES}

Figure Page

1. Perceived Capacity in Evaluation Objectives 32

2. Perceived Capacity in Data Collection 32

3. Perceived Capacity in Data Analysis 33

4. Perceived Capacity in Reporting Results 34

5. Perceived Importance of Evaluation Objectives 35

6. Perceived Importance of Data Collection 36

7. Perceived Importance of Data Analysis 37

8. Perceived Importance of Reporting Results 37

9. Perceived Need for Assistance with Evaluation Objectives 39

10. Perceived Need for Assistance with Data Collection 40

11. Perceived Need for Assistance with Data Analysis 40

12. Perceived Need for Assistance with Reporting Results 41 
Chapter 1

INTRODUCTION

Purpose

The Community Partnership of Santa Clara County is a coalition of public and private organizations involved in alcohol and other drug abuse prevention efforts within Santa Clara County. The Partnership is a five year effort funded by the federal Center for Substance Abuse Prevention (CSAP), formerly the Office of Substance Abuse Prevention (OSAP). Improving the evaluation capacity of member organizations is one of the Community Partnership's primary goals.

The purpose of this thesis was to assess the evaluation needs and capacities of member agencies within the Community Partnership. A telephone survey was developed and administered at the end of the Partnership's first year. The survey was designed to generate data which can be used by the Partnership to meet the evaluation needs of its members.

\section{Statement of the Problem}

The Community Partnership of Santa Clara County is a coalition of representatives from private and public organizations interested in developing coordinated, county-wide substance abuse prevention planning and programs. The coalition is funded by the federal Center for Substance Abuse Prevention (CSAP), Department of Health and Human Services, through a five year, 2.5 million dollar demonstration grant. Funding began in 
November, 1991.

The Community Partnership of Santa Clara County informally began when several individuals working in the area of substance abuse within the county began meeting in order to respond to a Request for Proposals (RFP) from the Office of Substance Abuse Prevention (OSAP). Although Santa Clara County had a long history of substance abuse treatment and prevention programs, many in this ad hoc group felt that the existing efforts had not been successful in alleviating the root causes of alcohol and drug problems. The group felt that existing programs had been neither coordinated nor comprehensive. They were also concerned that existing efforts focused on the individual rather than the community and would not lead to significant change in the social system within which drug abuse occurs.

The RFP offered a substantial opportunity to develop a coordinated prevention system to serve the numerous and diverse communities in Santa Clara County. With the assistance of a grant writer, the ad hoc group developed a proposal which was submitted to OSAP in the spring of 1991 . Santa Clara County was one of 251 communities across the country awarded a Community Partnership Demonstration Grant.

One of the first tasks of the new Community Partnership of Santa Clara County was to establish a mission. Specifically the mission was to initiate and support prevention activities through organizational collaboration and community involvement and to target the root causes of alcohol and other drug abuse (Anderson, 1990, p. 1). Ultimately, the Partnership hoped to develop a strategic blueprint for a long-term and integrated prevention system.

The Partnership set several long term goals and objectives, as well as yearly goals and objectives. The Partnership's long term goals were as follows: 
1) To build and support an ongoing county-wide partnership for alcohol and other drug abuse prevention.

2) To encourage cooperation and communication among individuals, groups, organizations, institutions, and businesses in order to promote the sharing of technology, skills, information, and resources to build community capacity for substance abuse prevention.

3) To develop, coordinate, and facilitate comprehensive programs, projects, and strategies that prevent alcohol and other drug problems.

4) To advocate for resources that sustain and support the mission of the Partnership.

5) To evaluate the effectiveness of the Partnership (Anderson, 1990, p. 1).

The Partnership's first year objectives stated that:

1) The Partnership will be established and recognized as a county-wide coalition of organizations, agencies, and community groups addressing alcohol and other drug (AOD) problems.

2) A comprehensive overview of AOD prevention efforts in the county, including current levels of service and prevention strategies, will be developed for use by the Partnership in planning and activities, and made available to the larger community.

3) A three- stage planning process will culminate in a strategic plan for the Partnership's first five years by October, 1992.

4) Coordination and communication among AOD prevention organizations will be increased and improved.

5) Accurate and current information on AOD prevention will be maintained and access to and use of that information will be increased. 
6) Alcohol and other drug prevention efforts among individuals, groups, and organizations in the community will be promoted and strengthened.

7) The community will be made more aware of AOD prevention efforts in the county.

8) By June, 1992, the first year process evaluation will be completed, baseline data for the outcome evaluation will be identified and/or gathered, and preparation for building evaluation capacity of members will be completed (Anderson, 1990, p. 1).

To help fulfill its long term goals and first year objectives, the Community Partnership included a comprehensive, collaborative evaluation component in its overall program design. The Partnership allocated 15 percent of its budget to evaluation and hired a team from San Jose State University to serve as internal and external evaluators. The evaluation was designed to measure three aspects of the Partnership: its process, outcome and impact. Additional information would be provided by a separate OSAPfunded meta-evaluation of all 251 Community Partnerships.

Included in the first year objectives was preparation for building the evaluation capacity of Partnership members. The Evaluation Team decided to begin this capacity building by assessing the evaluation-related needs and capacities of the organizations and agencies participating in the Partnership during its first year.

This research was designed to provide the baseline assessment of Partnership members' perceived evaluation needs. The researcher was part of the Evaluation Team (see Appendix A) and this particular study was part of the larger evaluation of the Community Partnership's first year (see Appendix B). The assessment, developed in 
consultation with Partnership staff and Evaluation Team members, was conducted in July and August, 1992.

\section{Limitations}

There are several limitations to this study. Some of the limitations stem from the particular methods of this study, while others are inherent in the general process of a community based assessment.

Information for this assessment was collected through the use of an original questionnaire administered over the telephone. Certain benefits and limitations are inherent in all telephone surveys. As suggested by Oyster, Hanten, and Llorens (1987), telephone interviews have the advantage of being less time consuming and less expensive than personal interviews. However, sampling can be difficult as telephone surveys present the problem of asking busy individuals to return messages, in this case, while at work. Telephone interviews also provide an easier "escape" for respondents who do not wish to participate, respondents who want to complete the process quickly, or those who wish to avoid questions that may be difficult to answer.

A second limitation of this study came from the use of an original questionnaire.

Due to competing evaluation demands and concerns of the Partnership staff, the questionnaire was never formally tested for validity and reliability. Timing of the survey was also problematic. Questionnaire development required considerable input from others, including Partnership staff and the other members of the Evaluation Team. As a result, the researcher had little control over the timing of the survey, which may have influenced both the response rate and the responses themselves. 
The third limitation relates to the sample selected for this study. A specific group of individuals, designated as "active members" by the Partnership staff, were invited to participate in the interviews. These 80 people may not be representative of other active members, or the Partnership as a whole. It should also be noted that the survey was administered to a select group of people in a particular partnership. While providing data about those individuals and the organizations they represent, specific results may not be generalizeable to other partnerships or other populations.

\section{Significance}

Despite its limitations, this research has significance for the Community Partnership of Santa Clara County, as well as for other organizations involved in prevention efforts.

This study will help the Community Partnership in a variety of ways. Development and implementation of the survey helped the Partnership meet its first year program goals. The findings will be central to the planning of the Partnership's subsequent activities. Specifically, the data profile member agency evaluation capacities as well as the respondents' perceived needs for evaluation assistance. These findings will help the Partnership prioritize its goals and objectives for the remaining years of funding.

The study also has significance for the individual organizations within the Community Partnership. Participation in the interview provided an opportunity for respondents to analyze the evaluation strengths and weaknesses of their organizations. This study also provided a mechanism for member organizations to provide input and feedback to the developing Community Partnership during its first year. 
This study may have significance beyond Santa Clara County. Apart from the Partnership, the data collected through this research may indicate the degree of evaluation need and capacity in other Bay Area agencies. Since most counties within the greater Bay Area have health and social service organizations similar to those in Santa Clara County, the broad findings may be of interest to planners and program officials in other communities.

This study also points out commonalties and differences across a number of agencies working in the same general area on the same issues. This assessment of evaluation-related strengths and weaknesses will assist in future planning and can help these organizations meet their own program objectives. Identifying strengths and weaknesses will also aid in future collaboration and training efforts, both within and beyond the Community Partnership. It is hoped that improved self-assessment, increased evaluation capacity, and relevant, coordinated efforts will make a significant contribution to more effective substance abuse prevention in Santa Clara County and beyond. 


\section{Chapter 2}

\section{REVIEW OF LITERATURE}

A successful program requires feedback to judge the worth of its activities and its overall effectiveness. Program evaluation is now commonplace among many types of service organizations, particularly social service organizations.

Evaluations are undertaken for different reasons: to judge the worth of ongoing programs, and to estimate the usefulness of attempts to improve them; to assess the utility of innovative programs and initiatives; to increase the effectiveness of program management and administration; and to meet various accountability requirements (Rossi \& Freeman, 1982, p. 15).

Shadish, Cook, and Leviton (1991) noted that the services provided by social programs aim to improve the welfare of individuals, organizations, and society. It is therefore useful to assess the degree to which any social program improves welfare, how it does so, and how it can do so more effectively.

"Program planning can be considered as part of an administrative cycle involving three phases: program planning, program implementation, and program evaluation. Evaluation is seen as a part of the program planning process" (Dignan \& Carr, 1981, p. 5). Dignan and Carr also point out that the program planning phase consists of defining the problem, establishing program goals, and conducting a community analysis. The program implementation phase includes the time in which program plans are carried out. The program evaluation phase is when the outcomes of the program are measured. This 
phase should include process evaluation, which adds a broader view of what has taken place, while considering the efficiency of the planning group's actions.

Marti-Costa and Serrano-Garcia (1983) see program evaluation, along with program planning, as tools whose purposes are to foster system maintenance and control. In addition, program evaluation can be used "to obtain additional funding for already established programs" (p. 79).

History of Evaluation

According to Rossi and Freeman (1982), "Over forty years ago, an Arkansas sociology professor pleaded for evaluations of President Roosevelt's New Deal social programs" (p. 21). Following this, social research, particularly evaluation research, received considerable attention. Its use increased during World War II as the U.S. Army worked to develop monitoring of soldier morale, and evaluation of personnel and propaganda policies.

Shortly thereafter, large scale programs designed to help meet Americans' healthrelated and social service needs were implemented. Since large amounts of money were required to implement these new programs, there was an increasing demand for knowledge of their results (Rossi \& Freeman, 1982).

Most social programs operated under the assumption that they were successful if people were being served. Evaluation, when done at all, was typically conducted to show how many people had been served, not how well they had been served. Evaluation research discovered that these programs were costly and that many were not delivering the intended services. As a result, some programs were eliminated altogether, and those that survived were forced to justify their continued existence. "Some of the programs didn't have a clear idea of why they were in existence in the first place, so the problem of justifying what they were doing really threw them for a loop" (Dignan \& Carr, 1987, p. 3). 
Program directors quickly discovered that evaluation research was a great way to produce evidence to justify their programs.

By 1950 , evaluations of health and social service programs were commonplace not only in America but in Europe and other industrialized countries as well. Evaluation methods were shared between countries and became widespread even in some of the lesser developed countries.

From the early 1960 s through the mid-1980s, the scientific literature on evaluation gave increasing rise to articles regarding the practice and methods of evaluation. Indeed, evaluation research was quickly becoming a growing industry (Rossi \& Freeman, 1982).

Recently there has been an even greater increase in interest and literature regarding program evaluation. The late 1980's and early 1990's have produced a change in the focus of evaluation. Mandates from the federal government for program evaluation have helped to influence these changes. Recent changes in evaluation have focused on expanding its scope from a merely quantitative measurement of program outcomes to include qualitative measures that can play an integral part in continuously shaping program planning, design, and implementation.

\section{Importance of Evaluation}

Evaluation can be an important part of program planning and functioning. As Rossi and Freeman (1989) point out, results of evaluation can be directed towards key individuals, such as program directors or public officials, who have the authority to allocate resources and shape a human service program. Dignan and Carr (1987) identify several important uses for evaluation. Evaluation can assess what has occured as a result of program plans and can measure if the program has been carried out in agreement with the program goals. Evaluation is also a necessary part of public relations. Periodic evaluation may help a program to maintain a good public image and ensure future funding. 
Many grants and funding sources require some type of structured evaluation. Increasingly, even state and county governments are requiring evaluation, or are required to perform rigorous evaluation, in order to justify basic social services. For example, the state of Minnesota mandates evaluation of each of the state's county-based social programs. Specifically, the "state legislation delegated Social Service funding decisions to county government while requiring counties to plan for and evaluate program effectiveness" (Kuechler, Velasquez, \& White, 1988, p. 71).

In a separate study, Velasquez, Kuechler, and White (1986) assessed the use of evaluation by decision makers at all levels of a county service delivery system. Again, the study was conducted in Ramsey County, Minnesota where evaluation is required by the state. This research found that department administrators value program evaluation results as one of many sources of information. Administrators use evaluation results to make policy decisions, support funding recommendations, examine trends, and identify problems. Department managers reported that evaluation results are important for helping them to define service needs, plan delivery strategies, identify program problems, develop budget recommendations, and identify training needs. Planning teams also considered evaluation to be valuable. These individuals use evaluation results to monitor program effectiveness, identify gaps in the service system, make runding recommendations, and to identify and act on problem performance in purchased programs. Program staff considered evaluation results to be valuable, particularly when advocating for funding. In summary, respondents at all levels considered evaluation to be useful and valuable.

Need for Evaluation Assistance

The Minnesota study by Velasquez and her colleagues (1986) also explored the evaluation interests of decision makers at all levels of the county service delivery system. The findings show that department administrators would like evaluators to continue to 
train them and their staff in the appropriate use of evaluation. Department managers have developed an interest in additional evaluation data. Planning teams would like to have more client satisfaction measures and client characteristic data included in evaluation. Overall, most respondents agreed that they still have much to learn about evaluation and expect the evaluation staff to continue to train them to use evaluation more quickly and effectively.

\section{Evaluation Methodology}

According to the literature, there are a variety of evaluation categories and models, all of which can be adapted to meet the specific needs of a particular study. Evaluation models tend to be more prescriptive, telling evaluators how to conduct evaluations, whereas evaluation categories are more descriptive and focus on certain aspects of the evaluative function.

The Standards Committee of the Evaluation Research Society has identified six categories of evaluation: (1) front-end analysis, (2) evaluability assessment, (3) formative evaluation, (4) impact evaluation, (5) program monitoring, and (6) evaluation of evaluation (Patton, 1982). These categories are not mutually exclusive, for many are used in conjunction with one another. Within these groups are numerous types of evaluation.

There are a number of different evaluation models in program evaluation literature. Some of the more common evaluation models include cost-benefit analysis, experimental or causal design, and the process, impact, and outcome model (which is often abbreviated to include only process and outcome). Other models are a combination or an adaptation of these models.

\section{Process and Outcome Evaluation}

The most commonly used model for the evaluation of social service programs at the current time is the process/outcome model. In this model, the process component 
focuses on assessing the theory and implementation of programs. The outcome component is used to determine if a program's objectives have been met (Patton, 1982).

Research performed by the Pawtucket Heart Health Program exhibits the strengths of process and outcome evaluation. This 1980 program was designed to document change in the cardiovascular disease risk status of residents in a city of 72,000 in the northeastern United States (McGraw, McKinlay, McClements, Lasater, Assaf, \& Carleton, 1989). Through process evaluation, the study was able to: (a) document the progress of the program, (b) document the presence of independently initiated activities in the intervention city and a comparison city, (c) provide rapid feedback to program staff regarding the impact of the intervention, (d) allow for evaluation of critical program components relevant to the successful or unsuccessful implementation of intervention programs, (e) provide a data base for cost-effective analyses of program components, and (f) permit planning for successful program replication in other communities as well as the continuation of the program.

The use of process evaluation enabled the staff to recruit participants, increase dissemination of nutrition kits, increase their understanding of the target population, and refine program planning and development. The use of outcome evaluation allowed the staff to measure the program's impact on the population (MicGraw et al., 1989).

Another study that reinforces the effectiveness of process and outcome evaluation is the Community-Based Respite Program in Chicago. The goal of this program was to offer support services to dependent, elderly persons and their caregivers in the family home or institutional setting. The program was a collaborative effort between a community hospital and a visiting nurses association (Pearson \& Theis, 1991).

The evaluation plan was designed to measure process variables which included activities and the delivery of services, as well as outcome variables which would measure 
goal attainment. Information gathered during process evaluation helped visiting nurses to understand which aspects they could control and which were beyond their control. This, in tum, significantly affected the quality of care delivered. The results also contributed to ongoing improvement of services.

The study which assessed the effectiveness of Forsyth County's project to prevent cervical cancer also utilized process evaluation to determine program effectiveness (Dignan, Michielutte, Sharp, Young, \& Daniels, 1991). The use of process evaluation made it possible to alter the program while it was still in operation and to improve services to the target population.

\section{Other Models}

A method that may be used in conjunction with process and outcome evaluation is cost-benefit analysis. This type of evaluation examines the monetary and human relationships between program costs and program outcome. These results not only assist in evaluating a program's effectiveness but can also help to estimate future program costs (Sherrill, 1984).

The experimental evaluation model is not often used for program evaluation because it is so difficult to carry out. In experimental evaluation, intervention and control groups are observed to measure whether or not there is a change as a result of a particular program. In the situation of social programs, it is difficult to control the environment so that no other variables affect the observed group. However, because "it is difficult to separate out the changes which are the result of a particular program from those which have occured in response to other events" (Rossi \& Williams, 1972, p. 29), program evaluators often utilize comparison groups in a quasi-experimental design.

Another method, not commonly used in social program evaluation, is naturalistic inquiry. Graduate students at Indiana University used naturalistic inquiry for evaluation of 
their graduate program in Occupational Therapy. In this study, information was gathered in a natural environment with the use of observation and interviews. As data was collected, it was immediately analyzed to provide direction for further data collection (Meyers, 1990). Although fewer programs utilize this approach, it can be extremely valuable within the framework of process evaluation.

\section{Implementation}

Implementation of program evaluation can be conducted in a variety of ways. Recent literature, however, strongly points to continual, collaborative evaluation.

Green, Kreuter, Deeds, and Partridge (1980) suggests six phases for program development in which evaluation is the final phase. However, they caution that "listing evaluation as the last phase is misleading. We consider evaluation to be an integral and continuous part of working with the entire framework" (Green et al., 1980, p. 16). Ross and Mico (1980) describe evaluation as " a continuous, systematic process of directly or indirectly observing, keeping pertinent record of, and objectively judging the extent to which a target behavior has changed so that the new behavior can be supported and reinforced and its future trend predicted" (Ross \& Mico, 1980, p. 257).

Once an intervention or program is planned and evaluation begins, there needs to be continual program monitoring and feedback (Hennessey, 1991). The Pawtucket Heart Health Program shows the benefit of collaborative, continual evaluation. Receiving rapid feedback regarding the impact of the intervention helped program staff to learn more about the participants and their needs. This information allowed staff to understand the needs and beliefs of participants and adjust their program approach (McGraw et al., 1989).

The Community-Based Respite Program, mentioned previously, also demonstrates the effectiveness of continual, collaborative evaluation. After the first year of data 
collection, several key program modifications were made in areas of project

implementation and collaboration (Pearson \& Theis, 1991).

\section{Internal vs. External Evaluators}

Internal evaluators are those evaluators who are employees of the organization for which they are performing the evaluation. External evaluators are those individuals or group of individuals hired solely for the purpose of evaluation and are not housed within the organization. Both internal and external evaluation practices have advantages and disadvantages.

In many cases, internal evaluators are program directors who have the additional responsibility of evaluating the program. In other cases, project employees may be hired specifically for evaluation. Internal evaluators have the advantage of knowing first hand the organization's philosophy, policies, procedures, products, personnel, and management. Another advantage is that internal evaluators are usually more cost effective than external evaluators. In addition, internal evaluators are often more available than external evaluators. One of the disadvantages of internal evaluators is that they may lack the technical expertise that external evaluators possess (Shadish et al., 1991).

External evaluators are often hired consultants with specialized skills in evaluation. One advantage of using external evaluators is their technical expertise. Another advantage of using external evaluators is their objectivity. Objectivity may be easier to maintain if the evaluator is not part of the program. A disadvantage of external evaluation is that it can be expensive. A second disadvantage is that external evaluators are often not available to evaluate specific program activities (Shadish et al., 1991). Evaluation of the Community Partnership

Evaluation of the Community Partnership of Santa Clara County utilized process and outcome evaluation and was conducted by a team of external evaluators (see 
Appendix B). This thesis research, a part of the broader first year evaluation, assessed the evaluation capacities, needs, and priorities of member agencies in order to determine the need for future evaluation assistance. 


\section{Chapter 3}

\section{METHODOLOGY}

This research was designed to assess the evaluation needs and capacities of member organizations of the Community Partnership of Santa Clara County. Specifically, this research asked the following questions:

1. What are member agencies' evaluation capacities?

2. What is the importance of evaluation for member agencies?

3 . What are the current evaluation needs of member agencies?

\section{$\underline{\text { Research Objectives }}$}

The research was conducted as part of a larger evaluation of the first year of the Community Partnership of Santa Clara County. This component of the evaluation was designed to meet the following objectives:

1. To assess the evaluation needs and interests of selected member agencies of the Community Partnership,

2. To provide baseline data which can be used to monitor progress of the Community Partnership towards meetings its own objective of enhancing member evaluation capacities,

3. To provide information that can be used by Community Partnership leaders and staff to determine program priorities and directions,

4. To provide a mechanism through which Partnership members could provide input into program direction, and

5. To contribute to the overall evaluation of the first year of the Community Partnership of Santa Clara County. 


\section{Definitions}

The following conceptual definitions were utilized in this research:

Community Partnership of Samta Clara County:

A coalition of public and private organizations involved in alcohol, drug, and other prevention efforts within Santa Clara County, funded by the Community Partnership Program of the Center for Substance Abuse Prevention.

Member Agencies:

The agencies or organizations that constitute the Community Partnership of Santa Clara County.

\section{Evaluation:}

"The process of determining the value or degree of success in achieving an objective, identification of the criteria to be used in measuring success, and determination and explanation of the degree of success. Evaluation is defined more broadly as the comparison of an object of interest against a standard of acceptability" (Green et al., 1980, p. xiv).

Need:

"A requirement an individual or group becomes aware of when values are acquired that demand certain levels of comfort or wellness" (Green et al., 1980, p. xv).

Resources:

Those materials and/or items which assist individuals or groups to meet their needs.

\section{Evaluation Capacity:}

The current ability of member organizations to meet their evaluation needs and interests. 
The following operational definitions were utilized in this study:

Member Agencies:

Organizations or agencies represented by anyone who has attended one or more Community Partnership meetings, has been involved in any Community Partnership activities, or has requested to be placed on the Community Partnership membership list.

\section{Evaluation:}

Any activity related to assessment or documentation of program process, outcomes, or impacts as reported by respondents.

Need:

Any evaluation-related deficiency or desire stated by respondents.

Resources:

All instruments, tools, information, and personnel pertaining to program evaluation available to member agencies as reported by respondents.

\section{Evaluation Capacity:}

The current evaluation skills, designs, procedures, and resources utilized by member agencies as reported by respondents.

\section{Study Design}

This study utilized a combination of two approaches to determine evaluation resources and the need for program evaluation assistance among the organizations represented by Community Partnership members. The study design offered flexibility and 
specificity while allowing the researcher to gather information from those individuals who would benefit from it the most.

An original survey was used to gather evaluation status survey data. Status surveys aim to collect data from a specific sample, which can then be used to generalize results to a larger population. This is one of the seven types of descriptive research, identified by Oyster, Hanten, and Llorens (1987), which describe and document phenomena. Status survey research may utilize direct or indirect contact with respondents. Direct contact, via telephone interview, was selected for this assessment.

This study also used a service population approach, one of the six key approaches to needs assessments (Spiegal \& Hyman, 1978). This approach allows the researcher to target a specific population. Responses are gathered from those persons actually utilizing the service. This approach was particularly appropriate for this research as accuracy and sample specificity were more important than generalizability to a broad population.

\section{Questionnaire}

The needs assessment was conducted through an original telephone survey which assessed active members' current evaluation capacities, current evaluation needs, and the priority of evaluation. A questionnaire was developed in collaboration with the Partnership Evaluation Team and key Partnership staff (see Appendix C). The survey instrument was pre-tested on two members of the Partnership's Leadership Team.

The questionnaire asked closed and open-ended questions to allow qualitative and quantitative data to be gathered. The survey was branched in order to accommodate individuals who conduct program evaluation themselves as well as those who do not. This branching allowed the interviewer to easily identify questions relevant to individual respondents. 


\section{Sample}

The sampling strategy was based on the service population assumption that the individuals being sampled should be those most likely to utilize the potential services. For this reason, it was decided to survey "active" Partnership members.

"Active Partnership members" were identified by a selection team consisting of the Partnership Director, Assistant Director, and Administrative Assistant. The selection of "active members" was based upon the number of recent meetings attended (a minimum of three), as well as the selection team's perception of each momber's degree of past involvement and participation. Individuals who had served on the Partnership's early leadership group (Transition Team) were also defined as "active members."

With these criteria, 80 of the 512 Partnership members (16\%) were identified as "active Partnership members" eligible for participation in the survey.

\section{Telephone Protocol}

A protocol was established to systematize the sampling process. An alphabetized list of the selected names and workplace telephone numbers was given to the researcher by Partnership staff. The researcher began calling members from the top of the alphabetized list. Those members not reached the first time were called again in the same order at a later date.

Data collection calls were made during the work day, Monday through Friday, between the hours of 9:00 a.m. and 5:00 p.m. from July 13, 1992 to August 8, 1992. Respondents were greeted, informed of the researcher's affiliation with the Community Partnership Evaluation Team, and told that their agency or organization had been chosen to be a part of the sample for the Community Partnership's member evaluation needs assessment. Respondents were informed that their responses would be confidential and that their answers would not be associated with their names or the names of their 
organizations. Respondents were then asked if they would like to participate in the study. Whenever possible, the interviews were conducted immediately, usually lasting 10-15 minutes. In order to maintain continuity during the interview process, a script was developed by the researcher (see Appendix D). Upon completion of the interview, participants were asked if they had any additional comments and then informed that they would receive results of the survey via the Community Partnership at a later date.

Individuals selected for the sample who were not knowledgeable about their agency's evaluation practices were asked to recommend another person from their agency who might be better able to answer the questionnaire.

\section{Informed Consent}

Because this study was part of a larger evaluation study supported by the Community Partnership grant, approval to proceed had been granted by the Committee for the Protection of Human Subjects of San Jose State University's Institutional Review Board (see Appendix E). The larger evaluation project qualified for exemption from the written informed consent procedures. However, informed participation was established for this needs assessment as respondents were informed early in the phone contact and prior to beginning the interview that their responses would be confidential. Respondents were also assured that their answers would not be associated with their name or the name of the organization which they represented. Following this, respondents were asked if they were interested in participating and were allowed to participate or decline participation. 
Analysis

Data analysis began once all phone interviews had been completed. Questionnaires were reviewed for completeness and segregated into two sets of data: questionnaires from those respondents whose organizations conduct program evaluation and questionnaires from those that do not conduct program evaluation. Frequencies and percentages for all pre-coded variables were calculated for both data sets. For uncoded, qualitative data, responses were reviewed and categories, as well as nominal lists, were created. Where appropriate, frequencies and percentages were calculated for the newly coded responses.

Most of the data collected for this study can be reported utilizing descriptive statistics. The most appropriate method of reporting the quantitative results is through the use of relative frequencies and percentages. Qualitative results are reported by major themes or categories. Tables and bar charts are used to display data as appropriate.

\section{Assumptions}

The design and implementation of this study were based on severai assumptions about the selected methods, the potential participants, the Community Partnership, and the broader social context within which alcohol and other drug abuse prevention programs must operate.

The research assumed that the current evaluation requirement of most social programs by their funding sources would create an interest among potential respondents in the area of evaluation. Funding sources are increasingly requiring evaluation in order to measure the effectiveness of many social service programs. For this reason, it was 
assumed that participants would be aware of these external demands and therefore interested in participating in the study.

Several assumptions implicit in this study pertain to the Community Partnership itself. First, this study assumed that individuals identified by the Partnership staff as "active members" would be aware of the Community Partnership and interested in its success. This study further assumed that the Community Partnership members were enthusiastic about the Partnership and willing to participate in its activities. Members who were enthusiastic about the Partnership and interested in its success were assumed to be interested in participating in this particular study. It was also assumed that contact with the researcher, identified as part of the independent Evaluation Team, would be welcomed by respondents.

The choice of methods for this study assumed that the telephone survey approach was an appropriate way to collect the desired information. The study assumed that the original questionnaire, developed specifically for this needs assessment, would collect reliable and valid data. The study also assumed that the researcher would operate independently and in a non-biased manner.

The design of this study also contains assumptions regarding participants. One such assumption was that the sample would reflect service users or potential service users in Santa Clara County. The study also assumed that the Community Partnership staff who selected the "active Partnership members" did so without bias and that their selection method was valid.

Finally, the study assumed that participants would answer the questionnaire honestly. It was assumed that the selected individuals would be available at the phone numbers listed on the Community Partnership membership list and would be able and willing to take the time to answer the questionnaire. 


\section{Chapter 4}

\section{RESULTS}

Data collection occured between July and August of 1992. A total of 80 individuals who had been identified as "active Partnership members" were eligible to participate in the study. In accordance with the study protocol, three telephone call attempts were made to each potential respondent (see Table 1).

Table 1

Results of Attempted Data Collection Calls

\begin{tabular}{lcccc}
\hline & Total calls & Successful data collection calls & Call not returned & No longer available \\
\hline 1st altempt & 80 & 25 & 49 & 6 \\
2nd attempt & 49 & 12 & 37 & 0 \\
3rd attempt & 37 & 3 & 34 & 0 \\
\hline Total & 166 & 40 & 120 & 6
\end{tabular}

Attempts were made to contact each of the 80 "active" Partnership members in the first round of calls. Of the initial 80 calls, only 25 resulted in a successful contact and a completed interview. Six of the 80 members could not be reached due to changes in phone number or workplace. Messages were left for the 49 members who could not be reached during the first round, requesting that they return the researcher's call. After contacting 49 of these individuals a second time, 12 calls resulted in completed interviews. Again, messages were left for those unavailable. A third attempt was made to contact 37 of the remaining names and data was collected from three of those members. 
Data collection closed in August after four weeks of sampling. The final sample of 40 respondents represented a $50 \%$ response rate from the initial list of eligible, active Partnership members.

\section{Program Evaluation Practices}

The following includes an analysis of questions answered by all respondents. As shown in Table 2,32 respondents $(80 \%)$ reported that their agency does conduct evaluations.

Table 2

Evaluation Requirements by Funding Source

\begin{tabular}{lllll}
\hline & \multicolumn{3}{c}{ Evaluation requirements } \\
\cline { 2 - 5 } & n & Required & Not required Required for some programs \\
\hline & 32 & 25 & 0 & 7 \\
Conduct evaluation & 8 & 0 & 8 & 0 \\
\hline Do not conduct evaluation & 8 & & $8(20 \%)$ & $7(17 \%)$ \\
\hline Total & 40 & $25(63 \%)$ & 8
\end{tabular}

Nearly two thirds of the respondents $(63 \%)$ are required by their funding sources to conduct evaluation. Only eight of the 40 organizations (20\%) are not required to perform evaluation. Seven $(17 \%)$ are only required to conduct evaluation for some of their programs. 
The following includes an analysis of those questions answered only by the 32 respondents whose organizations do conduct program evaluation.

Frequency of Evaluation

The frequency of evaluation varied among the respondents (see Table 3). Most reported that they conduct program evaluation either continuously (34\%), at the end of programs (26\%), or annually (28\%). Only four respondents reported other time frames. Of those who responded "other", one conducts evaluation twice per year, two conduct evaluation four times per year, and one respondent reported that the organization conducts evaluation once every three years.

Table 3

Frequency of Evaluation Within Organizations

\begin{tabular}{lcc}
\hline Frequency of evaluation & Frequency & Percent \\
\hline Continuously & 11 & $34 \%$ \\
At the cnd of a program & 8 & $26 \%$ \\
Annually & 9 & $28 \%$ \\
Other & 4 & $12 \%$ \\
\hline Total & 32 & $100 \%$
\end{tabular}

\section{Evaluation Staffing}

Half of those whose organizations perform evaluation reported that it is done by internal evaluators (see Table 4). Only three respondents reported that their organization relies entirely on external evaluators. Twelve respondents reported using both internal and external evaluators. Among the total of 15 organizations that utilize external evaluators, seven $(47 \%)$ hire private consultants and eight $(53 \%)$ use state auditors. 
Table 4

Evaluation Staffing

\begin{tabular}{lcc}
\hline Evaluation Staffing & Frequency & Percent \\
\hline Internal Evaluator & 17 & $53 \%$ \\
External Evaluator & 3 & $9 \%$ \\
Internal and External Evaluator & 12 & $38 \%$ \\
\hline Total & 32 & $100 \%$
\end{tabular}

\section{Satisfaction with Evaluation Staffing}

When respondents were asked whether or not they were satisfied with the evaluation staffing pattern used by their organization, $19(60 \%)$ responded yes, and 13 $(40 \%)$ responded that they were not satisfied. Reasons for the negative responses included; "it's contract compliance and it gets in the way," "it's not really outcome," "things are gathered and nothing is done," "it could be improved," and "it is heavily quantitative and I would like it to be more qualitative."

\section{Costs and Benefits of Evaluation}

Several themes emerged when Partnership members were asked what they considered to be some of the benefits as well as some of the costs of evaluation. The following list shows respondents' perceived benefits of evaluation, with the number of respondents citing each theme in parentheses:

- it allows you to monitor the program and to make adjustments if needed (12)

it helps to keep you focused on your mission and goals (7)

- it is helpful for future funding (3) 
- it incorporates client feedback (2)

- it helps in planning (1)

- it gives an in-depth assessment (1)

Some of the perceived costs of evaluation included:

- it is time consuming (10)

- it is costly (8)

- it creates additional paperwork (2)

- the measurement used to evaluate may not be effective (2)

- it requires quite a bit of energy (2)

- it disrupts work (1)

- it creates emotional stress (1)

Many respondents volunteered more than one comment on the benefits of evaluation. Few respondents volunteered more than one comment on the costs of evaluation, and two respondents had no response.

Perceived Capacity in Aspects of Evaluation

Partnership respondents were asked their perceptions of their organization's evaluation capacities in the areas of: (a) evaluation objectives, (b) data collection, (c) data analysis, and (d) reporting results. Specifically, participants were asked to rate their organization's capacity in each aspect as weak, adequate, strong, or uncertain (see Table 5). 
Table 5

Perceived Capacity in Aspects of Evaluation

\begin{tabular}{lllll}
\hline & \multicolumn{4}{c}{ Perceived capacity (n=32) } \\
\cline { 2 - 5 } Evaluation Aspects & Weak & Adequate & Strong & Uncertain \\
\hline Evaluation objectives & $8(25 \%)$ & $15(47 \%)$ & $6(19 \%)$ & $3(9 \%)$ \\
Data collection & $8(25 \%)$ & $15(47 \%)$ & $6(19 \%)$ & $3(9 \%)$ \\
Data analysis & $7(22 \%)$ & $14(43 \%)$ & $7(22 \%)$ & $4(13 \%)$ \\
Reporting results & $8(25 \%)$ & $12(38 \%)$ & $12(38 \%)$ & $0(0 \%)$ \\
\hline
\end{tabular}

Figure 1 demonstrates respondents' perceptions of their organization's current evaluation objectives. Almost half of the respondents (47\%) felt that their organization's evaluation objectives were adequate. However, a sizable proportion of respondents $(25 \%)$ answered that their objectives were weak. Only six of the respondents (19\%) reported their organization's evaluation objectives were strong. 


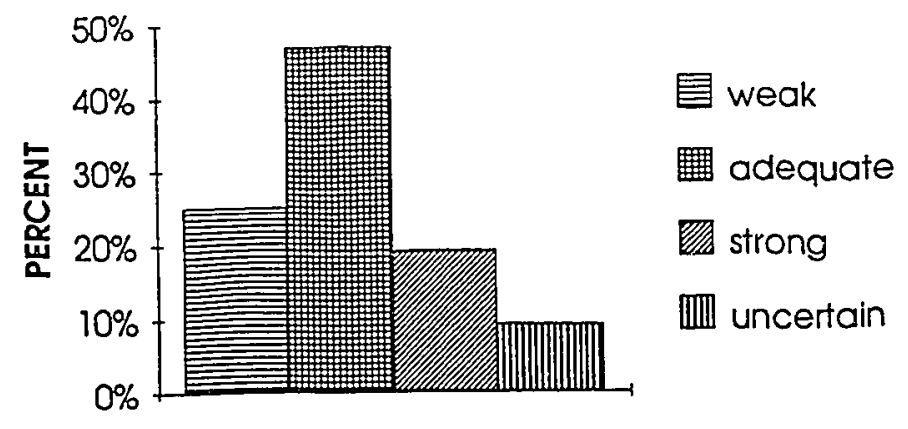

Perceived Capacity

Figure 1. Perceived Capacity in Evaluation Objectives

When asked to rate data collection capacities, the distribution of responses was quite similar to the responses regarding evaluation objectives (see Figure 2). Again, almost half of the respondents (47\%) answered that their organization's data collection capacities were adequate, while $25 \%$ considered their capacities to be weak, and $19 \%$ considered their organization's capacities to be strong.

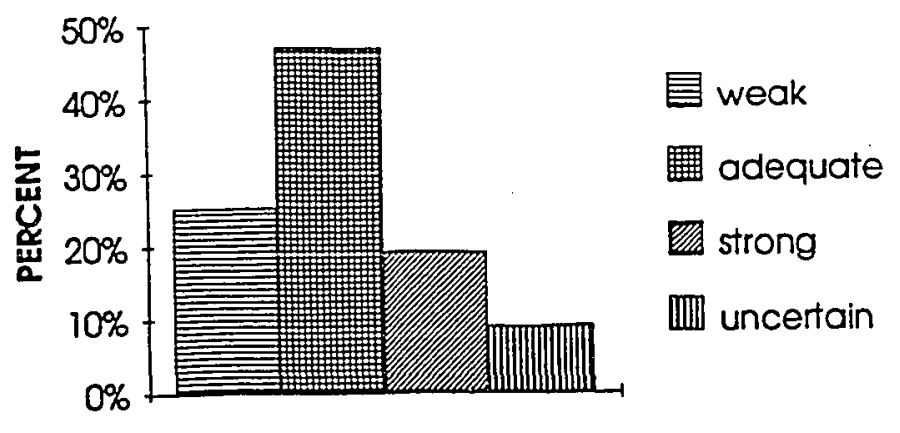

Perceived Capacity

Figure 2. Perceived Capacity in Data Collection 
Responses regarding data analysis capacities differed only slightly from those of evaluation objectives and data collection (see Figure 3 ). Here, the responses form a more normal distribution than the distributions regarding evaluation objectives and data collection. In terms of data analysis capacities, the same percentage of respondents (22\%) considered their organization's data analysis capacities to be weak as considered them to be strong. Fourteen (43\%) of the respondents considered their organization's data analysis capacities to be adequate.

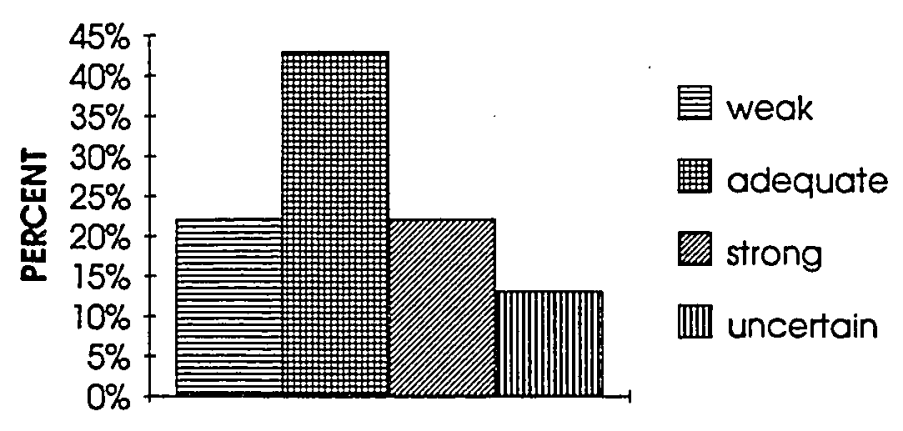

Perceived Capacity

Figure 3. Perceived Capacity in Data Analysis

Interestingly, when respondents were asked about their current capacities for reporting results, many more respondents replied that they were strong or adequate in this aspect of evaluation than had rated their organizations highly on the other three aspects (see Figure 4). While $38 \%$ of the respondents felt that they had strong abilities in reporting results and $38 \%$ felt as if they were adequate in this area, $25 \%$ felt that their organizations were weak in their ability to report evaluation results. 


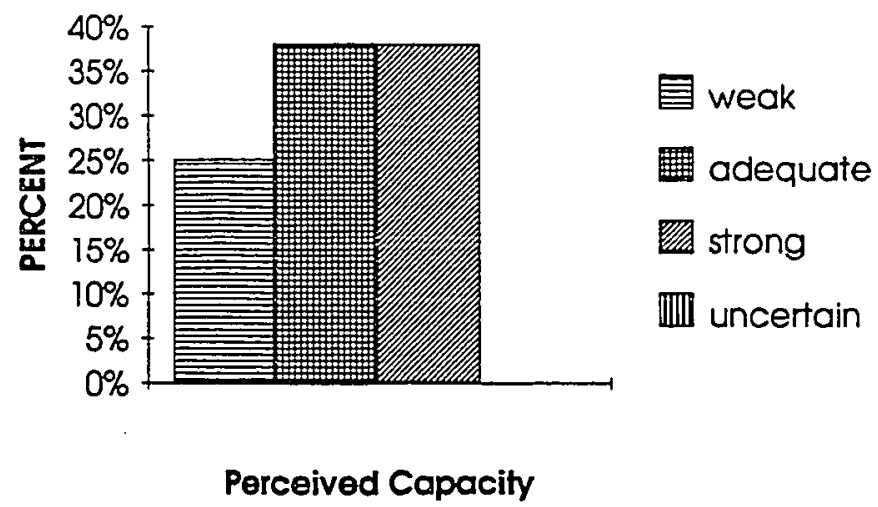

Figure 4. Perceived Capacity in Reporting Results

\section{Perceived Importance of the Four Aspects of Evaluation}

Respondents were asked to rate their perceptions of the importance of the four evaluation aspects to their own organizations. Specifically, respondents were asked whether their organizations would consider evaluation objectives, data collection, data analysis, and reporting results as unimportant, somewhat important, important, or uncertain (see Table 6). 
Table 6

Perceived Importance of Aspects of Evaluation

\begin{tabular}{lllll}
\hline & \multicolumn{4}{c}{ Level of importance (n=32) } \\
\cline { 2 - 5 } Evaluation Aspects & Unimportant & $\begin{array}{l}\text { Somewhat } \\
\text { Important }\end{array}$ & Important & Uncertain \\
\hline Evaluation objectives & $0(0 \%)$ & $5(16 \%)$ & $25(78 \%)$ & $2(6 \%)$ \\
Data collection & $0(0 \%)$ & $3(9 \%)$ & $27(84 \%)$ & $2(6 \%)$ \\
Data analysis & $0(0 \%)$ & $6(19 \%)$ & $22(69 \%)$ & $4(12 \%)$ \\
Reporting results & $0(0 \%)$ & $4(13 \%)$ & $28(87 \%)$ & $0(0 \%)$ \\
\hline
\end{tabular}

Figure 5 demonstrates the importance respondents gave to evaluation objectives. Over three fourths of those sampled (78\%) rated evaluation objectives as very important for their organizations as compared to the $16 \%$ that rated them as only somewhat important. No respondents rated evaluation objectives as unimportant.

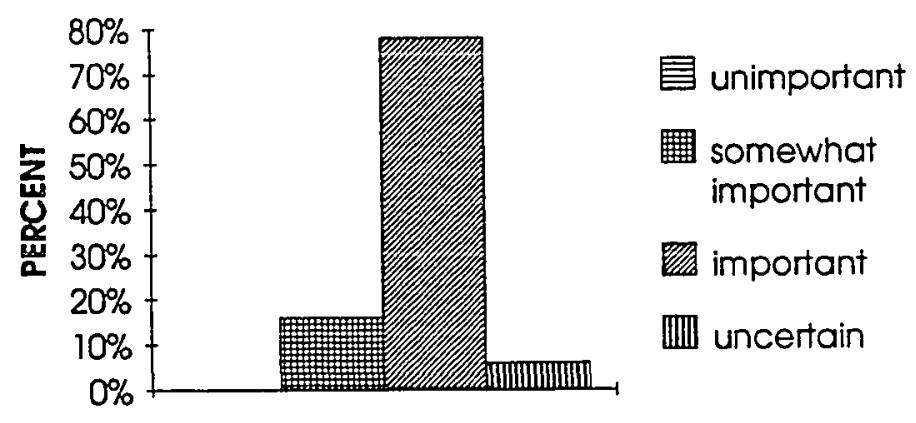

Perceived Importance

Figure 5. Perceived Importance of Evaluation Objectives 
The responses regarding the importance of data collection again show that a large proportion of respondents ( $84 \%)$ rated data collection as important to their organizations. A smaller number $(9 \%)$ rated data collection as only somewhat important, while no respondents rated data collection as unimportant (see Figure 6).

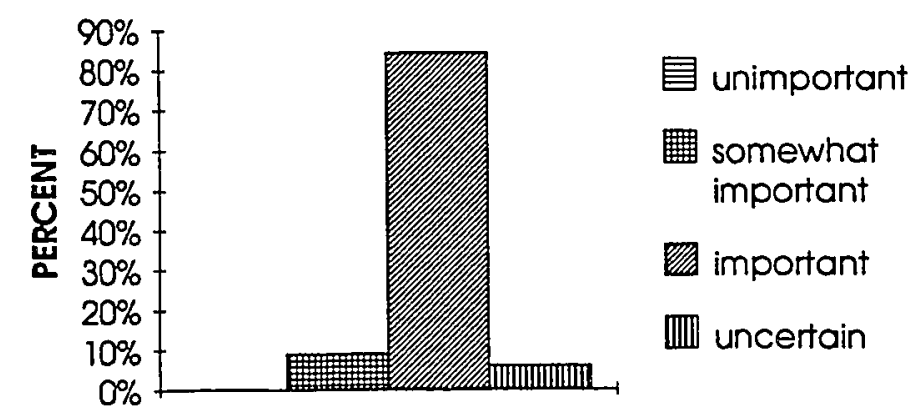

\section{Perceived Importance}

Figure 6. Perceived Importance of Data Collection

Figure 7 graphically displays respondents' ratings of the importance of data analysis to their organizations. A large portion of the sample (69\%) felt that data analysis is important. Four respondents replied that they were uncertain of the importance of this aspect to their organization. 


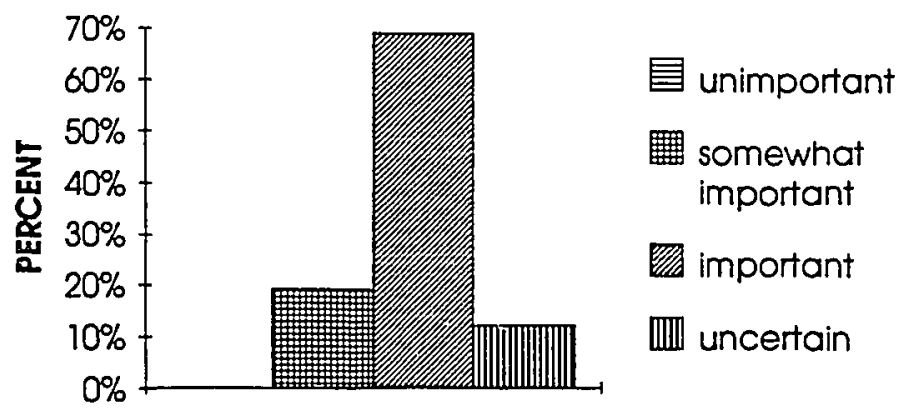

Perceived Importance

Figure 7. Perceived Importance of Data Analysis

Perceptions of the importance of reporting results were similar to those of the other three aspects of evaluation (see Figure 8). An overwhelming proportion (87\%) rated reporting results as important to their organizations, while only $13 \%$ rated reporting results as somewhat important. No one felt that reporting results was unimportant to their organization.

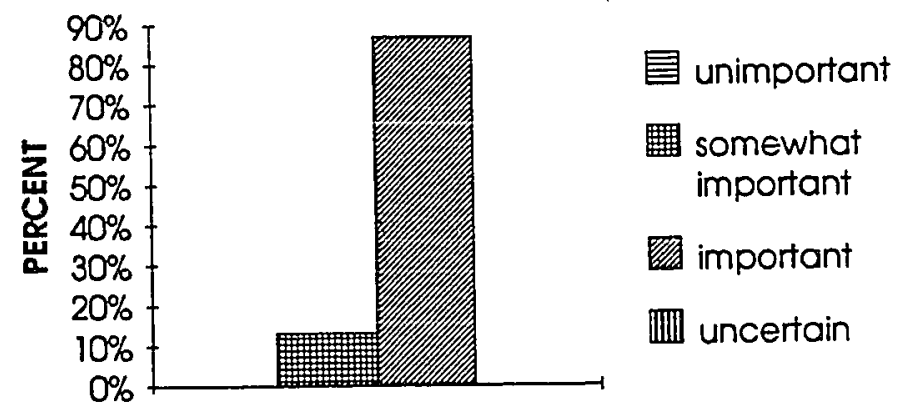

Perceived Importance

Figure 8. Perceived Importance of Reporting Results 
Perceived Needs for Evaluation Assistance

Respondents were asked about their perceptions of their organization's current need for evaluation assistance. The respondents were specifically asked if they felt their organization had no need, some need, a significant need for assistance, or if they were uncertain (see Table 7). Findings regarding respondents' needs for assistance in each evaluation area are discussed below.

Table 7

Perceived Need for Evaluation Assistance

Level of need $(n=32)$

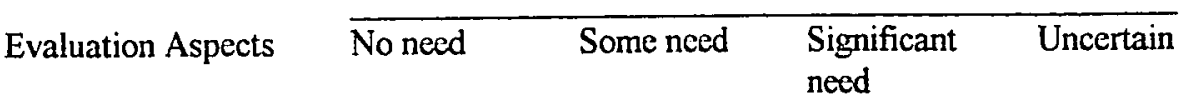

\begin{tabular}{lllll}
\hline Evaluation objectives & $4(12 \%)$ & $14(44 \%)$ & $13(41 \%)$ & $1(3 \%)$ \\
Data collection & $4(13 \%)$ & $14(44 \%)$ & $11(34 \%)$ & $3(9 \%)$ \\
Data analysis & $4(13 \%)$ & $14(44 \%)$ & $11(34 \%)$ & $3(9 \%)$ \\
Reporting results & $6(19 \%)$ & $16(50 \%)$ & $10(31 \%)$ & $0(0 \%)$ \\
\hline
\end{tabular}

Figure 9 graphically demonstrates respondents' ratings of their organization's need for technical assistance in the area of evaluation objectives. The distribution of organizations with some need and those with a significant need is nearly even. While nearly half of the respondents (44\%) reported that their organizations had some need for assistance with evaluation objectives, $41 \%$ perceived a significant need for assistance in 
this area. Only four respondents (12\%) replied that their organizations had no need for assistance with evaluation objectives.

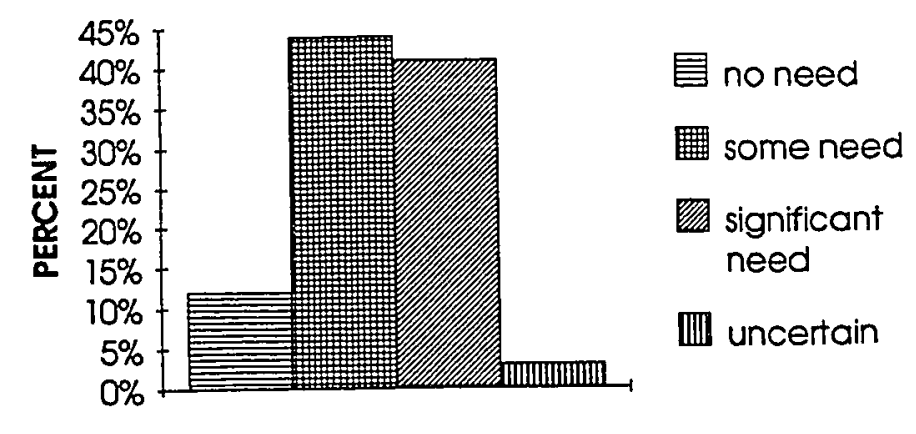

Perceived Noed

Figure 9. Perceived Need for Assistance with Evaluation Objectives

Figure 10 graphically demonstrates findings regarding data collection. The percentage of those with some need for assistance with evaluation-related data collection is greater than the percentage of those with a significant need. While $44 \%$ replied that they had some need for assistance, $34 \%$ responded that they had a significant need for assistance in this area. Only four respondents (13\%) replied that their organizations had no need for assistance with data coliection. 


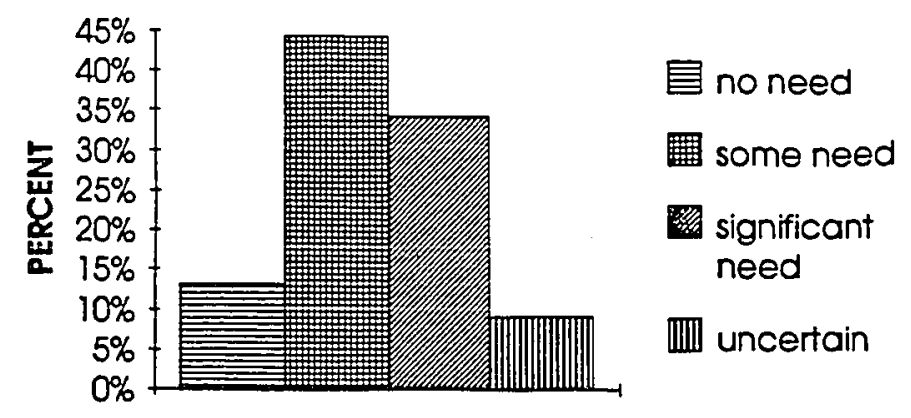

\section{Perceived Need}

Figure 10. Perceived Need for Assistance with Data Collection

Respondents' ratings regarding data analysis were identical to the distribution of responses regarding data collection. Again, $44 \%$ replied that their organizations had some need for assistance with data analysis, 34\% responded that their organizations had a significant need for assistance, and only $13 \%$ responded that their organizations had no need for assistance with analysis of evaluation data (see Figure 11).

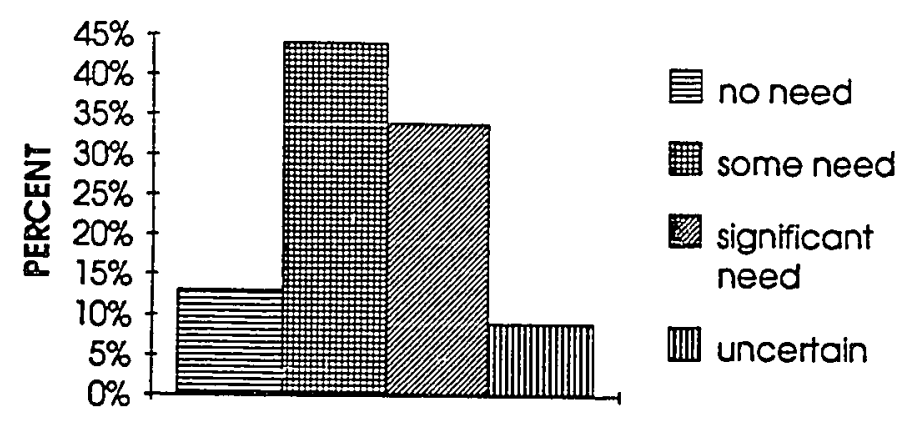

\section{Porceived Neod}

Figure 11. Perceived Need for Assistance with Data Analysis 
Responses regarding the need for assistance with reporting results differed slightly from the other three aspects of evaluation (see Figure 12). Half of the respondents (50\%) felt that their organization had some need for assistance, while a smaller proportion (31\%) felt they had a significant need for assistance with reporting resuits. When contrasted with the responses regarding the need for assistance in the other three aspects of evaluation, a larger number of respondents $(19 \%)$ perceived that their organizations had no need for assistance in reporting evaluation results.

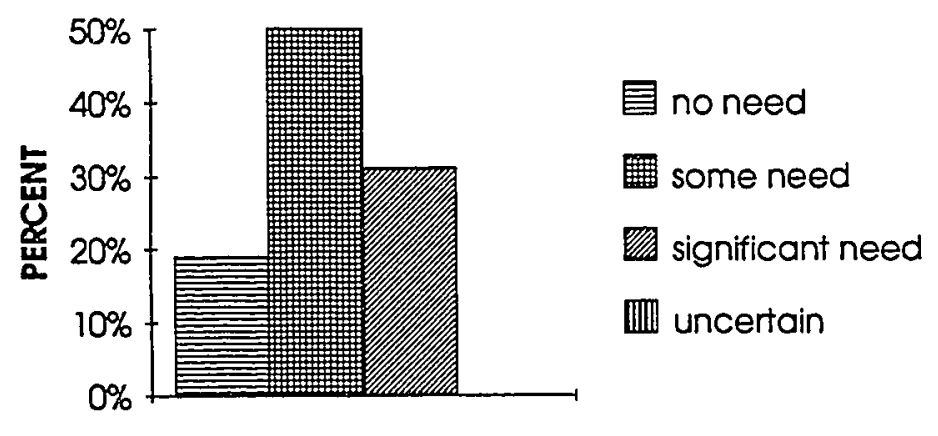

\section{Perceived Need}

Figure 12. Perceived Need for Assistance with Reporting Results

\section{Partnership Members who do not Conduct Evaluation}

Separate questions were asked of the eight respondents (18\%) who reported that their organizations do not conduct program evaluation.

The first question asked respondents if program evaluation was important to their organizations. Possible responses included yes, no, or other (see Table 8). Of the eight respondents, five (63\%) indicated that program evaluation is important to their agency, one said that it is not important, and two gave other responses. Specifically, the two other 
responses were "evaluation is not important at this point, but will be later", and "this would not apply to our organization."

Table 8

Perceived Importance of Evaluation Among Members Who Do Not Conduct Evaluation

\begin{tabular}{lcc}
\hline Perceived Importance of Evaluation & Frequency & Percent \\
\hline Important & 5 & $63 \%$ \\
Not important & 1 & $12 \%$ \\
Other & 2 & $25 \%$ \\
\hline Total & 8 & $100 \%$
\end{tabular}

This group of respondents was also asked why their organizations do not conduct program evaluation. Seven of the respondents replied; "our organization is just startingup but plans on conducting program evaluation." The only other response to this question came from a respondent who stated; " we merely do research and are not funded to conduct evaluation in all cases."

When respondents were asked if their organizations had ever considered conducting program evaluation, five $(63 \%)$ indicated that their organizations had considered it. Three respondents qualified their response with the following comments; "We are just beginning the program and have not yet discussed evaluation," "our program is too young at this point to have discussed evaluation," and "this is not applicable to my organization." No one said that their organizations had not considered evaluation (see Table 9). 
Table 9

Consideration of Conducting Evaluation

\begin{tabular}{lcc}
\hline Consideration of Evaluation & Frequency & Percent \\
\hline Yes & 5 & $63 \%$ \\
No & 0 & $0 \%$ \\
Other & 3 & $37 \%$ \\
\hline Total & 8 & $100 \%$
\end{tabular}

Interest in Evaluation Assistance

All 40 respondents, whether their organizations conduct program evaluation or not, were asked the last two questions of the survey. The first question asked respondents if they would be interested in receiving evaluation technical assistance if it were offered by the Community Partnership of Santa Clara County. Overwhelmingly, the answer was yes, with $34(85 \%)$ answering that they would be interested in receiving technical assistance and two responding that they might be interested depending on the circumstances, particularly time and cost. Only four respondents (10\%) said that they would not be interested in receiving technical assistance in evaluation from the Community Partnership.

The final question asked about the best format for the technical assistance. Overall, the majority of respondents were more interested in a workshop than one-on-one technical assistance. In fact, only one respondent expressed an interest in individual consultation. Three respondents specified that they would be interested in an inexpensive workshop that dealt with all aspects of evaluation. Two respondents mentioned that due to budget cuts in their agencies, they would be particularly interested in a workshop that dealt with program evaluation on a low budget. 


\section{Chapter 5}

\section{DISCUSSION}

The purpose of this study was to assess the evaluation needs and capacities of member agencies within the Community Partnership of Santa Clara County.

\section{Evaluation Capacities of Member Agencies}

The results of this study clearly suggest that most of the organizations represented by active members do conduct some type of program evaluation on a regular basis and most are required to conduct evaluation.

In general, the respondents indicated that the member organizations' evaluation capacities across all four aspects (i.e., evaluation objectives, data collection, data analysis, and reporting results) were adequate or strong. Many respondents $(47 \%)$ felt that their organization's evaluation objective and data collection capacities were adequate, while $43 \%$ considered their organization's data analysis capacities to be adequate. Reporting results was one area in which many respondents (38\%) considered their organization's capacities to be strong. Several respondents offered additional information regarding the reporting of results in their organizations and gave detailed examples of the methods used. In addition, several respondents offered to assist in an evaluation workshop where they would share their ideas and expertise.

The results suggest that respondents possessed more expertise and knowledge regarding evaluation than was anticipated by the researcher. The majority of respondents were extremely knowledgeable about the four areas of evaluation and their organization's evaluation practices reflect this knowledge. 


\section{Perceived Importance of Evaluation Among Member Agencies}

Respondents considered evaluation important since many funding sources now require evaluation for continued financial support. In addition, respondents viewed reporting results more important than data collection, evaluation objectives, and data analysis, in that order. None of the four evaluation aspects were considered unimportant. Although reporting results was considered to be the most important aspect of evaluation, respondents felt that their organizations had less need for assistance in this aspect than any other aspect. This is not surprising since most program evaluators in the organizations surveyed are not professional evaluators but, instead, are program directors with significant experience in writing reports and reporting results.

Need for Evaluation Assistance Among Member Agencies

Individual respondents still felt a need for evaluation assistance within their organizations despite their level of knowledge in the area. Individual members' responses regarding their organization's need for evaluation assistance centered around some need or a significant need in all four aspects of evaluation. Most respondents felt that, regardless of their current evaluation capacities, more information about evaluation is always beneficial. In addition, five of the eight respondents whose organizations do not conduct evaluation considered evaluation to be important, and voiced an interest in gaining evaluation assistance.

The large percentage of respondents viewing their organization's capacities as adequate, and the large percentage of respondents indicating a need for assistance within their organization, suggest that the surveyed members desire information regarding new ideas and tools for evaluation, rather than information regarding basic program evaluation. It seems that Partnership members are in need of ideas for creating more effective and efficient evaluation within their organization, rather than ideas regarding the process of 
how to begin evaluation. However, the five organizations that have considered conducting evaluation but have not yet started, and the two organizations that are so new that they have not even thought about evaluation, may need more in-depth assistance.

Although most feel evaluation is important, and many organizations are required to conduct it, few respondents felt their organizations possess the level of expertise and financial resources needed for a comprehensive evaluation. Also, as pointed out by several respondents, many of the agencies surveyed are experiencing significant budget cuts. Some volunteered that an inexpensive and comprehensive evaluation workshop would be ideal. Over three fourths of all respondents indicated that they would be interested in receiving evaluation assistance, and all, except one, favored evaluation workshops over one-on-one assistance.

Throughout the survey, respondents stressed that while evaluation helps in program planning and helps to keep a program focused on its mission and goals, it also disrupts work, requires energy, is time consuming, and creates emotional stress. Learning to alleviate some of these perceived costs would be beneficial to many members.

Respondents indicated a significant need for evaluation assistance in the area of evaluation objectives and felt that their least need for assistance was in the area of reporting results. Miany Parinership members are experienced in reporting program results since continued or additional funding is often conditional upon program outcomes. Evaluation assistance that emphasizes how to develop and assess evaluation objectives would be beneficial to Partnership member organizations.

Three respondents added that they would be interested in an inexpensive workshop that dealt with all aspects of evaluation. Two respondents also mentioned that due to budget cuts in their agencies, they would be particularly interested in a workshop that dealt with program evaluation on a low budget. It would seem that such a workshop 
should deal with creating more efficient evaluation methods and procedures. Respondents could be trained to analyze their own evaluation components and be provided with ideas for improving their efficiency. In addition, the workshop could also provide Partnership members with ideas regarding developing new, innovative evaluation tools on a low budget.

\section{Discussion of Methods}

Because this study was part of a larger project, developing the questionnaire required more review than usual. The questionnaire passed through several rounds of review by the Community Partnership staff and the Evaluation Team. One advantage to this process was the additional input. Both the Evaluation Team and Community Partnership staff helped to point out ambiguous questions and information that may have been overlooked. Although the review process was tedious, it was beneficial and helped to improve the quality of the data collection instrument.

The disadvantage of this elaborate review process was the difficulty inherent in collaboration. Many creative and interesting ideas were offered by Partnership staff and Evaluation Team members. These ideas did not always correspond with one another or with the overall goals of the survey. Developing a consensus among these various players took considerable time and effort.

\section{Selection of Participants}

The original intent of this study was to survey active Community Partnership members to determine their evaluation capacities, priorities, and needs. The survey would assist in planning technical assistance for Partnership members that addressed their priority topics. Originally, the Evaluation Team hoped to randomly select a sample of 100 active Community Partnership members. Based on the Partnership's early plans and first year projections, it seemed as though selecting 100 "active members" would be quite simple. 
The process of selecting active members for the survey was not simple. As of late spring, 1992, criteria for membership had not been formally defined by the Community Partnership. For a number of political reasons beyond the scope of this research, "membership" during the time of this survey was informally defined as appearance on the Partnership's mailing list. Indeed, the mailing list was called the membership list. Appearance on the membership list had little to do with active involvement in the Community Partnership. The mailing list consisted of over 500 names, including anyone who ever attended a Community Partnership meeting or activity, anyone simply asking to be placed on the list, or anyone recommended by someone in the Partnership. Obtaining a meaningful sample of active members from the list of 500 names became extremely difficult. Partnership members could not be randomly selected from the list since many had simply been signed up for the Partnership by a friend, or had signed up and never attended a meeting. In addition, the list had been constructed without any type of sorting, coding, or sequencing which made identifying duplicates or multiple representation from the same organization impossible to detect.

Despite these problems, the Partnership staff were quite convinced that they could identify a meaningful sample of active members. However, this sample would be hand selected, representing a significant departure from the original protocol. Reluctantily, the researcher and Evaluation Team members agreed to this plan.

The Partnership staff recommended 80 individuals for the study. The staff selected the 80 members based upon the number of General Partnership meetings attended over the past 9 months, as well as their subjective assessment of a high degree of past involvement and/or current participation in the Community Partnership. In addition, anyone who had attended any of the three preceding monthly Partnership meetings was considered an 
active member, as were those individuals who had been part of the Partnership's early Transition Team.

Despite the researcher's discomfort with this development, selective sampling had one important advantage: The individuals to be contacted would, most likely, be the same individuals who would utilize the services which would be developed as a result of the survey. Since the purpose of this research was, above all, a needs assessment to support a developing program, this advantage was an important one.

An unexpected disadvantage of the selective sampling emerged not from the approach itself, but rather from the use of the Partnership staff to select the study participants. Allowing the staff to select 80 members created high expectations of sample size and data collection. The staff assumed that all 80 members could be reached and interviewed. They also assumed that all 80 individuals would gladly participate. This was not the case, and resulted in disappointment among Partnership staff.

Another fundamental disadvantage of allowing the Partnership staff to choose participants was the serious possibility that their selected sample might not be legitimate. Indeed, the 80 active members were not all active Partnership members. This became very clear during data collection. Several individuals who had been identified and called for an interview knew very little about the Partnership. In other cases, it appeared that the staff had wanted to use the survey for public relations with city officials or key people in the community, which sometimes resulted in embarrassing confusion when dealing with busy leaders' office staff.

\section{Timing of Data Collection}

Because this assessment was part of a larger project, it was necessary for the survey to maintain its place in the project's overall time line. The survey was originally scheduled to be conducted in March, 1992. However, the unanticipated delay in 
administering a preceding survey caused the evaluation needs assessment to be delayed four months. As a result, this survey was postponed until July, 1992. The delay caused the survey to be conducted during the summer which created difficulties in reaching many participants. As might be expected, many potential participants were on vacation, or away from the office for extended periods of time. The state's budget crisis during those months also contributed to difficulty in reaching members for a phone interview.

In addition to the difficulties contacting respondents, sampling was further complicated by two other surveys from the Partnership which were being conducted at the same time. One of these surveys was a mail questionnaire created by the Evaluation Team to evaluate the Partnership's first year performance. This survey was sent to all 500 names on the Community Partnership mailing list. Originally scheduled for early spring distribution, that survey was delayed until summer for many of the same collaboration dynamics described previously. The second survey was an unexpected needs assessment created and administered by a team of communications specialists from Stanford University who were hired by the Partnership staff.

The presence of three surveys may have created confusion among some potential respondents. Two of the respondents telephoned for this survey mistook the phone call for a follow up call related to the Evaluation Team's first year performance survey. Another respondent mistook the phone call for a follow up call for the communications survey. Other respondents also stated their confusion regarding the three surveys.

The confusion did not seem to affect members' willingness to participate in this particular survey once they were reached by phone. However, the confusion may have been a key reason for the surprisingly low rate of returned phone calls from individuals from the selected sample. 
Only 25 of the 80 sample names could be reached and interviewed on the first call. Of the 55 individuals called, but not available, 49 did not return the call as requested. The retum call rate was only slightly better on the second and third attempt. With such little support from Partnership members, data collection was much slower and more difficult than expected.

Trust

A final limitation to this study revolves around trust and the lack of anonymity between researcher and respondents. Originally, it was assumed that selection of "active members" and potential respondents' familiarity with the Partnership staff and evaluators would be assets in data collection. As it turned out, emerging problems within the Partnership may have caused potential participants to be reluctant to volunteer information. In addition, participants may have feared that honest information would jeopardize their organizations, their own positions, or their relationships with other organizations. The Partnership consists of many agencies who are in competition for funds with other member agencies. These individuals may also have feared divulging too much information to the Partnership.

\section{Contributions of the Research}

Despite the limitations inherent in this study, valuable information was obtained. Many Community Partnership members have similar programs, interests, and even funding sources. The data collected from the 40 respondents will be useful in enhancing the evaluation capacities of Community Partnership members.

The information obtained by this study will also help the Community Partnership staff monitor their own progress. The data and feedback from this assessment serves as a baseline from which the Partnership can measure its future effectiveness. 
This assessment also allowed a large number of Partnership members to voice their needs and provide input that could be communicated to the Partnership in a systematic manner. This input provided the Community Partnership staff with invaluable knowledge for determining future priorities and directions. 


\section{Chapter 6 \\ RECOMMENDATIONS}

Recommendations based upon the results of the study can be directed towards the Community Partnership Evaluation Team, the Community Partnership staff, and evaluation of community based programs.

Recommendations to Community Partnership Evaluation Team

This needs assessment was conducted to determine the evaluation capacities and needs of the Community Partnership of Santa Clara County and elicited data that will be important in developing evaluation assistance to meet these needs.

The first recommendation includes designing an evaluation workshop, or a series of workshops, on evaluation issues. Of the 40 respondents, $36(90 \%)$ were interested in technical assistance for evaluation. Of these 36 respondents, only one desired one-on-one technical assistance, while all others were more interested in an inexpensive, comprehensive workshop.

A second recommendation is to design the workshop(s) to reach all levels of evaluation knowledge and skill. Evaluation capacities and expertise were found to vary among Partnership member agencies. Across all four areas of evaluation (evaluation objectives, data collection, data analysis, and reporting results), the majority of members considered their capacities as adequate. The area of reporting results was the only area where as many respondents considered themselves strong as considered themselves adequate. None of the respondents viewed any of the four areas as unimportant.

A third recommendation for the Evaluation Team is to emphasize activities which help Partnership members to form more effective evaluation objectives and develop new 
techniques for data collection and analysis. This would be beneficial since the majority of respondents viewed these areas of evaluation as important.

A fourth recommendation to the Evaluation Team concerns working with the Community Partnership staff. Because the Partnership staff favors a careful and comprehensive internal review process, the Evaluation Team should plan for lengthy review periods for future activities and evaluation projects.

A fourth recommendation is that the Evaluation Team adhere more closely to its own timelines in order to maintain some control over the timing of its surveys. In addition, the Evaluation Team should more closely monitor other surveys and data collection activities related to the Partnership.

An additional recommendation to the Community Partnership Evaluation Team is to emphasize its independence from the Community Partnership. During data collection for this study, Partnership members were very willing to speak freely to the researcher about their experiences with the Community Partnership. Maintaining independence from the Partnership will help build trust between the Evaluation Team and Partnership members, an important component for future data collection.

One final recommendation for the Evaluation Team is to utilize the existing expertise among Partnership members. Many of the members are experienced in the area of evaluation, eager to learn more, and willing to help others. This could be of real benefit as the Evaluation Team expands its efforts in future years.

\section{Recommendations to Community Partnership Staff}

An important recommendation to the Community Partnership staff is that they utilize the results of this study as soon as possible. Conducting the survey raised the expectations of the participants. If nothing is implemented that can be linked to the survey results, participants may doubt the Partnership's true interest in their input. One 
immediate activity is the establishment of the evaluation workshop(s) mentioned previously by so many respondents as the best method of assistance. Another recommendation to the Partnership staff is to quickly share the results of this survey. Several respondents specifically indicated an interest in receiving the survey results and other respondents will, most likely, appreciate seeing their own responses in context.

Another recommendation to the Community Partnership staff is to be aware of the expertise and interests of its members. During data collection, several members mentioned special interests and expertise in program evaluation. Utilizing these individuals as resources would be beneficial to other Partnership members and would help increase collaboration within the Partnership.

Another very important recommendation to the Community Partnership staff is to redefine "active members." The definition of an active member should be defined so that membership in the Partnership is more meaningful. This will not only help with future data collection but will also help the camaraderie among the truly active Partnership members.

One final recommendation for the Community Partnership staff is to carefully monitor overall Partnership activities so that there are only a few things occurring at one time. This scheduling of events will help to increase participation in Partnership activities. Recommendations for Evaluation of Community Based Programs

Even though this study was specific to the Community Partnership of Santa Clara County, it has implications for the general area of health education research and evaluation.

One general recommendation to health educators concerns the use of the service population approach with a selective sample. In this particular study, the method of selecting the sample was plausible and seemed to elicit "reliable" results. In future 
research situations where results can affect services to a selected group of individuals, it may again be best to directly survey those who will receive the service. The use of the telephone survey method was an effective means of obtaining results in a short amount of time and on a limited budget.

A second general recommendation for health educators concerns scheduling of surveys. Surveys should be scheduled during times when respondents will be easily accessible. As much as possible, researchers should avoid creating a burden for respondents with their surveys. Surveys which are difficult to answer, excessively long, or require a lot of time and effort to answer are a burden for participants. It is best to keep questionnaires as easy as possible for respondents.

One final recommendation for health educators involves continued research in the area of evaluation needs of social service agencies. It is commonplace for social service organizations to evaluate themselves. However, the methods used for evaluation are often primitive and inadequate. This study suggests that many individuals in social service agencies are eager to learn more regarding evaluation and have an interest in improving their programs in any way possible. Most are aware that program evaluation is the first step towards positive change within agencies and are therefore interested in improving program evaluation so that they, in turn, can improve the impact and effectiveness of their programs.

Evaluation is often seen as the comerstone to improving social service organizations. Studies such as this can indicate the evaluation needs and capacities of agencies so central to prevention and public health. Assessing the evaluation needs and assisting with improving evaluation capacity are important steps towards more efficient and effective social service programs. 


\section{REFERENCES}

Anderson, N. (1990). Santa Clara Valley OSAP Partnership grant. San Jose, CA.

Dignan, M. B., \& Carr, P. A. (1981). Introduction to program planning: A basic text for community health education. Philadelphia: Lea \& Febiger.

Dignan, M. B., \& Carr, P. A. (1987). Program planning for health education and health promotion. Philadelphia: Lea \& Febiger.

Dignan, M., Michielutte, R., Sharp, P., Young, L., \& Daniels, L. (1991). Use of process evaluation to guide health education in Forsyth County's project to prevent cervical cancer. Public Health Reports, 106(1), 73-77.

Green, L. W., Kreuter, M. W., Deeds, S. G., \& Partridge, K. B. (1980). Health education planning: A diagnostic approach. Palo Alto, CA: Mayfield.

Hennessy, M. (1991). Designing and evaluating alcohol problem community interventions: Quasi-lessons from the experience of medical trials. Journal of Primary Prevention, 11(3), 169-188.

Kuechler, C. F., Velasquez, J. S., \& White, M. S. (1988). An assessment of human services program outcome measures: Are they credible, feasible, useful? Administration in Social Work, 12 (3), 71-89.

Marti-Costa, S., \& Serrano-Garcia, I. (1983). Needs assessment and community development: An ideological perspective. Prevention in Human Services, 2(4), 75-89.

McGraw, S., McKinlay, S. M., McClements, L., Lasater, T. M., Assaf, A., \& Carleton A. (1989). Methods in program evaluation: The process evaluation system of the Pawtucket Heart Health Program. Evaluation Review, 13(5), 459-479.

Meyers, S. K. (1990). Program evaluation for accreditation. The American Joumal of Occupational Therapy, 44(9), 823-826.

Oyster, C. K., Hanten, W. P., \& Llorens, L. A. (1987). Introduction to research: A guide for the health science professional. Philadelphia: Lippincott.

Patton, M. Q. (1982). Practical evaluation. Beverly Hills: Sage. 
Pearson, M., \& Theis, S. L. (1991). Program evaluation application of a comprehensive model for a community based respite program. Journal of Community Health Nursing, $\underline{8}(1), 25-31$.

Ross, H., \& Mico, P. (1980). Theory and practice in health education. Palo Alto, CA: Mayfield.

Rossi, P. H., \& Freeman, H. E. (1982). Evaluation a systematic approach (2nd ed.). Beverly Hills: Sage.

Rossi, P. H., \& Freeman, H. E. (1989). Evaluation a systematic approach. (4th ed.). Newbury Park, CA: Sage.

Rossi, P. H., \& Williams, W. (1972). Evaluating social programs. New York: Seminar Press.

Shadish, W. R., Cook, T. D., \& Leviton, L. C. (1991). Foundations of program evaluation. Newbury Park, CA: Sage.

Sherrill, S. (1984). Toward a coherent view of evaluation. Evaluation Review, $\underline{8}(4)$, 443-465.

Spiegel, A. \& Hyman, H. (1978). Basic health planning methods. Maryland: Aspen Systems.

Velazquez, J. S., Kuechler, C. F., \& White, M. S. (1986). Use of formative evaluation in a human services department. Administration in Social Work, 10(2), 67-77. 


\section{BIBLIOGRAPHY}

California State Department of Finance. (1991). California statistical abstract 1991. Sacramento, CA: U.S. Government Printing Office.

Caputo, R. K. (1988). The tao of evaluation: Deriving good from flawed methodology. Administration in Social Work, 12(3), 61-69.

Crane, J. A. (1988). Evaluation as a scientific research. Evaluation Review, 12(5), 467-481.

Darrah, C., Perales, D., Radlefinger, S., \& Roe, K. (1992). The Community Partnership of Santa Clara County evaluation plan. San Jose, CA.

Dignan, M. B. (1986). Measurement and evaluation of health education. Springfield, IL: Charles C. Thomas.

Holder, H. D., \& Kibel, B. M. (1991, October). A community-systems approach to alcohol and other drug problem prevention. Paper presented at the First International Drug Abuse Prevention Research Symposium, Lexington, KY.

Leukfeld, C. G., \& Bukoski, W. J. (1991). Drug abuse prevention evaluation methodology: A bright future. Journal of Drug Education, 21(3), 191-201.

Love, A. J. (1991). Internal evaluation: Building organizations from within. New York: Sage.

Shadish, W. R. Jr., \& Epstein, R. (1987). Patterns of program evaluation practice among members of the evaluation research society and evaluation network. Evaluation Review, 11(5), 555-575. 
APPENDIX A

List of Evaluation Team Members 
Evaluation Team Members

Evaluators

\section{Chuck Darrah}

570 Church St.

Mountain View, Ca. 94041

home (415) 967-2591

work (408) 924-5314

\section{Dan Perales}

4409 Water Oak Ct.

Concord, Ca. 94521

home (408) 356-4398

work (408) 924-7559

\section{Sam Radelfinger}

8414 Hihn Rd.

Ben Lomond, Ca. 95005

home (408) 336-2996

work (408) 924-2980

\section{Kathleen Roe}

153 Los Altos Ave.

Walnut Creek, Ca. 94598

home (510) 944-0567

work (510) 944-0570 $\underline{\text { Research Assistants }}$

Delýna Cruz

870 E. El Camino \#304

Sunnyvale, Ca. 94087

home (408) 736-7939

\section{Kathleen MacKenzie}

P.O. Box 316

Pacific Grove, Ca. 93950

home (408) 394-1542 


\section{APPENDIX B}

\section{Partnership's First Year Evaluation Goals}




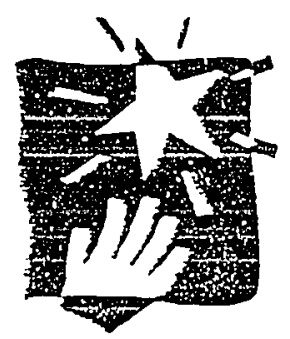

Communt: Parnersinp of Santa C'ara Eunty

\section{E:aluation $T \geq 3 m$}

C"ucx Darron . Y.P.t... ?h.

iritropology Eeoarment

San Jose State iniversity

Daniel Persies. M.P.R. Dr.P.:.

:iesith Science Deoartinem

San jose State Linversity

Sam Radieifinger. M.P.H. EiD.

Hieath Sctence Ieparment

San Jose Stale iniversiry

\section{COMMUNITY PARTVERSTIP OF SAYTA CLARA COLNTY}

\section{Eraiuation Goais. zuestions, and Ylethods}

Ziviteen Roe. M.P.Y. Di.?. .

Ferith Science Eeparment

jan jose State Linverstry

?! zase send correstcreescu :0:

TeE Evauation Team:

इiCO-iB Clayten Rcad. $=250$

Eorcord. CA $9452:-3105$

October 1, 1992 


\author{
EVALUATION OF THE \\ COMMUNTY PARTNERSHIP OF SANTA CLARA COLNTY: \\ Evaluation Goals, Questions. and Methods
}

\begin{abstract}
Sverview
The evaiuation of the Community Partnersinip of Santa Clara County is a collaborative, interactive effort between Parinership members, staff, and evaluators. The evaluation is designed to help the Partnership succeed.
\end{abstract}

The formal goals of the evaluation are:

1. To contribute to the effectiveness of the Community Partnership in meeting its mission and goals;

2. To assist in building evaluation capacity and commitment among Parinership member organizations and individuais;

3. To ciearly describe the process by which the Community Partnership responded ic the opportunity presented by CSAP's Partinersinip Program;

4. To determine the short and long term effects of the Partnersinip in Santa Clara County, and

5. To generate information (i.e.. data. lessons. recommendations) which will contribute to the growing body of applied knowledge regarding alconol and other drug abuse prevention, broad-based coalition efforts, communiry pianning, development and evaluation. and the evaluation of sociai change.

Since the primary goal of the evaluation is to support and enhance the Parnership's ability to grow, to learn, and to achieve its goais, the evaiuation design incorporates the principles of interactive planning and rapid feedback. The design enabies the evaluation team to assist the members and staff by describing the process and exploring the varied outcomes of Partnership efforts. The team will also attempt to offer additional perspectives by exploring Partnership activities and outcomes within the broader organizationai, social, and historical contexts relevant to participants.

The evaluation is being conducted by a team of evaluators from San Jose State University. The four team members, all protessors at SISL', have expertise in the fields of planning and evaluation, cultural anthropology, community organization and advocacy, multicultural communication, training, and systems science. The Team is privileged to be able to draw upon the skills of several SJSU students who serve as Research Assistants on the project. The Evaluation Team also works collaboratively, whenever possible, with evaluators of other California Partnerships and with the Pacific Institute for Research and Evaluation (PIRE). 


\section{Evaluation Gluesticrs}

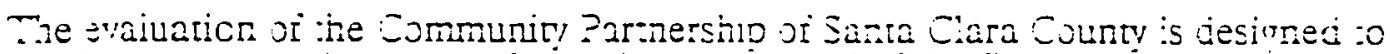

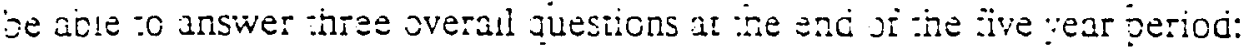

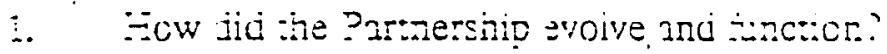

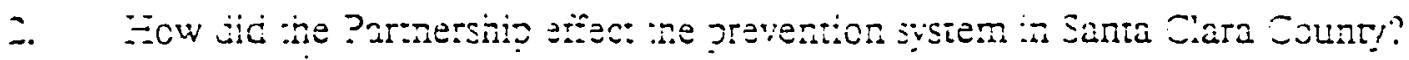

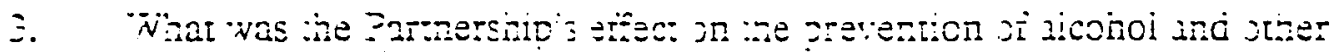
ing acuse. anc zther :eiaied sccial grodiems?

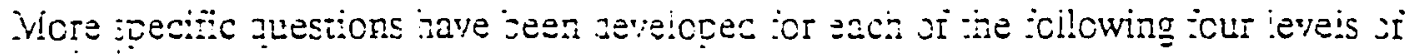
anaiysis.

$$
\text { Parmerinip- yvei }
$$

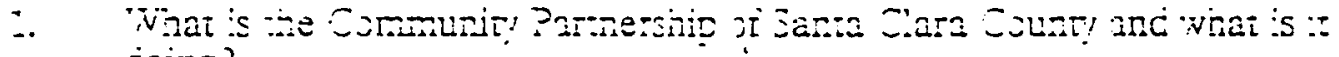
¿cing.'

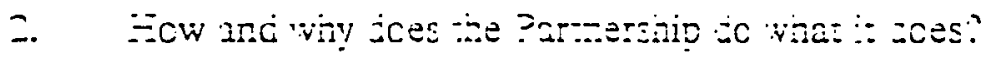

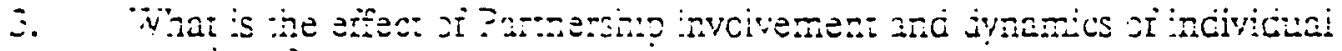
menicers?

\section{Imari-aticnai}

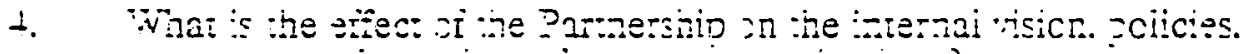

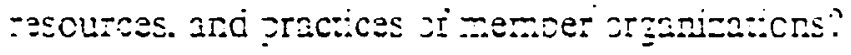

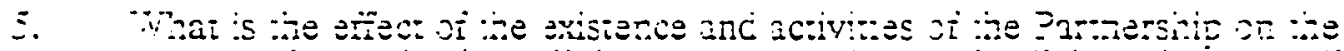

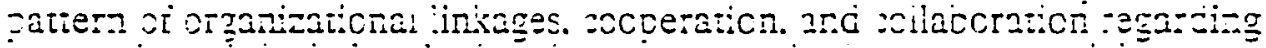

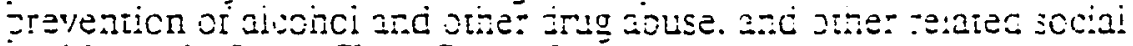
prodiems, in Santa Cara Count?

\section{E.mmunit: - Eve!}

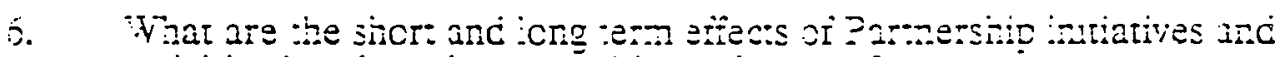
activizies in jeiected :onmúrites anc grouts?

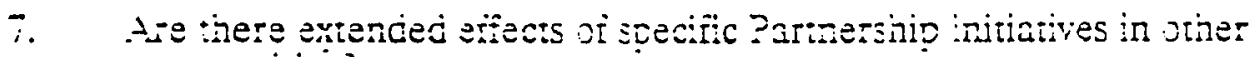
communities:

\section{Santa :Dara Eann: 'zuei}

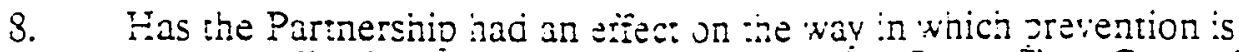
onceptuailzed. operationaiizes. and incied in Santa -"ara Cound? 


\section{Methods}

The Evaluation Team uses a variety of methods and data sources to document and analyze the growth and impact of the Community Partnership. Our goal is to provide a moving picture of Partnership eiforts in a manner that provides maximum feedback and learning opportunities for members and staff.

Our specific evaluation methods include:

1. Participant observation, in which Evaluation Tam members participate in Parmership activities, take extensive field notes. and then analyze those notes to uncover themes, patterns, key decision, and iurning points in the development of the Partnersinip.

2. Rapid̉ response feedback, suci as evaiuations of specific meetings, questionnaires aî the end of training sessions, and other auick surveys that provide iniormation "on the spot" regarding dynamics, content, and benetits of selected Partnership activities.

3. Interviewing, including regular debriering of staif and special interviews with participants in selected Partnership acivities. Interviews with specific groups of people. "key informants", allow the Evaluation Ieam to probe specific events or turning points in depth.

4. Focus groups. in which small groups discuss issues, findings, or experiences uentiried by the Evaiuation Team as potentiaily imporiant. These discussions provide invaluable opporunities for the Evaluation Team to get in depth information about participants' perceptions and experiences.

5. Archival research, in which the Team collects and reviews meeting minutes. personal notes, official and unofficial documents. and other printed material in order to understand the public and more privare history of the Partnership.

6. Aggregated data analysis. particularly using census data and the Councy Master Plan. whicin enables the Team to undersiand the context in which the Partnership is operating and trace the ways in which that contex might effect the Partnership's goals, activities, and success.

7. Written surveys, which ask both detailed and open-ended questions on critical areas such as leadersinip, role clarity, decision making, and cultural sensitivity. The first survey provided a baseline profile of the Parinership, its dynamics. its potential. and its challenges which will serve as a point of comparison over the next four years.

8. Telephone surveys of people who attend General Membership Meetings. are used to assess assessed members' perceptions. needs, and concerns regarding specific areas such as evaluation capacity and resources.

9. Analysis of Partnership objectives and activities allows the team to monitor the objective progress of the Partnersinip as reilected by its activities and accomplisinments. The original grant proposal, the annual workplans, and the quarterly reports io CSAP are examples of the kinds of documents used to compare and analyze the Partnership's plans and acrivities. 


\section{Time Frame and Sharing of Results}

Evaluation of the Community Partnership is an ongoing, interactive effort. In order to anchor the evaluation, October 1991, the iirst month of CSAP funding, has been established as the beginning of a year long baseline (October 1991 - September 1992). Althougn our designation of the "first vear" differs from that of CSAP (which declared Year One to cover the 10 month period October 1991 - July 1902), the Evaluation Team felt that, particulariy in the first year, a full 12 months of development was necessary for the Parnersinip to draw and develop its baseline. The "second vear" evaluation will cover a shorter period so that the evaluation year and CSAP's funding year will better coincide.

The Evaluation Team is committed io an open and accessible evaluation process. The Team welcomes the participation oi all members and staff in the creation of data collection instruments and the interpretation of results. While responses from individuais are always held in the strictest coniidence, aggregate data are available for revie'w and discussion.

The Evaluation Team regulariy prepares reports of specific data collection activities. These reporis are availabie at no cost to Partnership members (Please see the separate list of availabie reporis). Reports are available througn the Community Partnership Office or can je obtained by contacting the Evaluation Team directly at:

The Evaluaticn Team of ine Community Partnership

$5100-i B$ Clavton Road. 2250

Concord, Caijornia 94521-316

or by calling Dan Perales at (408) 0ニ4-75ミ0.

$10 / 1 / 92$ 
APPENDIX C

Questionnaire 
COMMUNITY PARTNERSHIP OF SANTA CLARA COUNTY

\section{EVALUATION NEEDS ASSESSMENT TELEPHONE QUESTIONNAIRE}

Telephone Questionnaire

1. Does your organization conduct program evaluation?

_ yes

no

2. Is your organization required by its funding source(s) to conduct program evaluation?

yes

no

other

if no, go to question $\# 12$

if yes, go to question \#3-11

3a. Is your evaluation conducted by an internal or external evaluator(s).

b. If evaluation is conducted by an internal evaluator, what is the title of the person who is responsible? and who do they report to?

c. If evaluation is conducted by an external source, what type of agency is responsible?

4a. Are you satisfied with this internal/external approach to evaluation?

b. If no, why not?

5. How frequently is evaluation conducted within your organization?

6a. What are the benefits to your organization in terms of evaluation?

b. What are the costs to your organization in terms of evaluation?

*The following grid will be used to chart responses to questions \#7-9. 
QESTR.XLS

\begin{tabular}{|l|l|l|l|}
\hline Evaluation Areas & Capacities & Importance & Need \\
\hline Evaluation Objectives & & & \\
\hline & & & \\
\hline Data Collection & & & \\
\hline & & & \\
\hline Data Analysis & & & \\
\hline & & & \\
\hline
\end{tabular}


7. Rate your organization's present evaluation capacity in terms of the four evaluation areas listed above as either weak, adequate, strong, or uncertain.

8. Rate the importance of each of the four evaluation areas as either important, somewhat important, important, or uncertain.

9. Rate the level of your organization's need for technical assistance in each of the four evaluation areas as either no need, some need, significant need, or uncertain.

10. Would your organization be interested in receiving technical assistance for evaluation if it were provided by the Partnership?

Yes
No
$\ldots$ Other ( Please designate)

11. Would your organization be more interested in receiving one on one technical assistance, or workshops?

\section{*Stop here}

12. Do you feel that program evaluation is important to your agency?

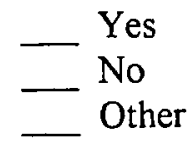

*If yes, go to question \#10

*If no, stop here

13. Has your organization ever considered conducting evaluation?

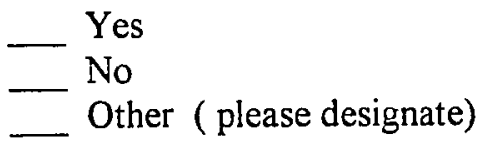

14. Why doesn't your organization conduct program evaluation? 
APPENDIX D

Script for Interviews 
Hello my name is Delyna Cruz and I'mi from the San Jose State eualuat:ion team for the Community Partnership of Santa Clara County. The reason that I'm calining is because your organization has been chosen to be a part of the sample for the Partnership's membership evaluation reeds assessment. This needs assessment will indicate to the Partnership what some evaluation needs are of Fartnership members.

I can assure you that your responses will be confidential in that your responses will not be matched to you or your organization.

The questionnaire takes approximately ten minutes. Do you have a bit of time right now to answer the questionnaire?

Yes - we continue on no- is there another time? if not, find another to sample.

If you need any clarification for any of the questions just let me knoll.

question \#1

question $\# 2$

branch out appropriately from 2

question $\$ 3 a$

question \#3b, add clarification if needed- is there a specific person resporisible for evaluation. What is their title?

question \#3c, add examples- a university or a private consultant.

question $\$ a, b$ and $c$

question \#5, may need to add clapification as to what consitutes being "eualuated". Eualuation will be considered as any documented evaluation of progress.

question $* 6 a, b$, and $c$

In questions $?-10$ l'm going to ask you three questions concerning four different areas, or components of evaluation. I'll tell you those areas right now, then l'll ask you the questions. The first area is evaluation object ives-this is any objectives your organization has set for its evaluation component. Objectives that address how your organization will evaluate itself. The second area is data collection. This includes any instruments that you may use to evaluate, including qual itative and quant itative methods of collecting data regarding your organizat ion's progress and performance. The third area of evaluation is data analysis. This area deals with interpreting the findings either the qualitative stat.istics, the words, or the quantitive statistics, the numbers. The founth area is reporting results. This includes reports, data presentations, and recommendations. 
How, I will ask you 3 questions regarding each of those areas; dor't worry after every question 1 will ask you for your response in each area individually, you won't need to remember all of those areas.

question $\$$ ?

Hame each area, individually, and list response.

question $\$ 8$

Mame each area, individually, and list response.

question $\# g$

Hame each area, indiuidually, and list response.

Now back to a straight foruard question

question $\$ 10$

Stop here if respondent. answered yes to question \#2

If coming from question \#2 with a no response:

question $\# 11$

question $\$ 12$

branch appropriately

Closure

Is there anything else you would like to add regarding evaluation. Tharik you very much for your participatian this is going to be a great help for the Partnership and I really appreciate your time, i will let you know the results after the data has been analyzed. Thank you again for your time. 
APPENDIX E

Human Subjects Approval 
To: Kathleen Roe

Health Science

San Jose State University

From: Serena w. Stanford ferene Sh thanfore
AAVP, Graduate studies and Research
Date: November 20,1991

As required by University policy, the Human subjects Institutional Review Board has reviewed your proposed project entitled:

"Evaluation of Santa Clara County Partnership"

Because your project is to be limited to the collection of data, by the observation of public behavior, in such a way that subjects cannot be linked to or identified with the data, your project is exempt from further review. Therefore, you may proceed without further review by the Human Subjects Institutional Review Board.

I, however, do caution you that whenever people participate in your research as human subjects, they should be appropriately protected from risk. This includes the protection of the anonymity of the subjects: identity with regard to any and all data that may be collected from the subjects. If at any time a subject becomes injured or complains of injury, you must notify Dr. Serena stanford immediately. Injury includes but is not limited to bodily harm, psychological trauma and release of potentially damaging personal information.

If you have questions, please contact me at 408-924-2480. 